\title{
Fixed Points of Closed and Compact Composite Sequences of Operators and Projectors in a Class of Banach Spaces
}

\author{
M. De la Sen \\ Faculty of Science and Technology, University of the Basque Country, Campus of Leioa (Bizkaia), \\ Apartado 644, Bilbao, 48940 Leioa, Spain
}

Correspondence should be addressed to M. De la Sen; manuel.delasen@ehu.es

Received 29 August 2012; Accepted 28 November 2012

Academic Editor: Alicia Cordero

Copyright (C) 2013 M. De la Sen. This is an open access article distributed under the Creative Commons Attribution License, which permits unrestricted use, distribution, and reproduction in any medium, provided the original work is properly cited.

\begin{abstract}
Some results on fixed points related to the contractive compositions of bounded operators in a class of complete metric spaces which can be also considered as Banach's spaces are discussed through the paper. The class of composite operators under study can include, in particular, sequences of projection operators under, in general, oblique projective operators. In this paper we are concerned with composite operators which include sequences of pairs of contractive operators involving, in general, oblique projection operators. The results are generalized to sequences of, in general, nonconstant bounded closed operators which can have bounded, closed, and compact limit operators, such that the relevant composite sequences are also compact operators. It is proven that in both cases, Banach contraction principle guarantees the existence of unique fixed points under contractive conditions.
\end{abstract}

\section{Introduction}

Some results on fixed points related to the contractive compositions of bounded operators in a class of complete metric spaces $(X, d)$, which are Banach spaces if $X$ is a vector space on a certain field $F$ (usually $\mathbf{R}$ or $\mathbf{C}$ ) and the metric is homogeneous and translation-invariant, are discussed through the paper. In this case, the metric $d$ is also a norm and, since the space $X$ is a vector space the complete metric space $(X, d)$ is also a Banach space $(X,\|\|)$. The class of composite operators under study can include, in particular, sequences of projection operators under, in general, oblique projective operators. Section 2 is concerned of composite operators which include sequences of pairs of contractive operators including, in general, oblique projection operators in the operator composite strip. The results are generalized in Section 3 to sequences of, in general, nonconstant bounded closed operators which can have bounded, closed, and compact limits, such that the relevant composite sequences are also compact operators. It is proven in this paper that Banach contraction principle [1-4] guarantees the existence of unique fixed points under contractive conditions fulfilled by some relevant strips of composite operators within in the whole composite sequence of operators.

\section{Some Results on Contractive Mappings and Fixed Points under Projection Operators}

Let $\left\{T_{k}\right\}$ be a sequence $T_{k}: X \rightarrow X$ of self-mappings on $X$, where $(X, d)$ is a metric space and consider a sequence $\left\{P_{k}\right\}$ of (non-necessarily orthogonal) projection operators on $X$ of respective ranges $M_{k}$ which are then closed subspaces of $X$, [3]. We can then consider a sequence of projection operators $\left\{P_{M_{k}}\right\}$ with $P_{M_{k}}: X \rightarrow M_{k}$ such that $P_{k}=P_{M_{k}}$ so that $X=$ $\operatorname{Im} P_{k} \oplus \operatorname{Ker} P_{k}$ and $z=P_{k} x \in \operatorname{Im} P_{k}$ is in $M_{k}$ for any $x \in$ $X$ and $\bar{z}=x-z=\left(I-P_{k}\right) x \in \operatorname{Ker} P_{k}$ for $k \in \mathbf{N}_{0}=\mathbf{N} \cup\{0\}$. Now, consider sequences $\left\{x_{k}\right\}$ in $X$ and $\left\{z_{k}\right\}$ in $M_{k}$ with $z_{k}=$ $P_{k} x_{k}$ such that the identities

$$
\begin{aligned}
x_{k+1} & =T_{k} x_{k}=P_{k+1} x_{k+1}+\left(I-P_{k+1}\right) x_{k+1} \\
& =z_{k+1}+\left(I-P_{k+1}\right) x_{k+1} \\
& =T_{k} P_{k} x_{k}+T_{k}\left(I-P_{k}\right) x_{k}
\end{aligned}
$$

hold by construction for $k \in \mathbf{N}_{0}$. The subsequent result holds.

Theorem 1. Assume that $(X, d)$ is a complete metric space with the metric $d: X \times X \rightarrow \mathbf{R}_{0+}$ being homogeneous 
and translation-invariant and $0 \in X ; k \in \mathbf{N}_{0}$. The following properties hold.

(i) If all the self-mappings on $X$ in the sequence $\left\{T_{k}\right\}$ are nonexpansive and the sequence of projection operators $\left\{P_{k}\right\}$ from $X$ to the sequence of subspaces $\left\{M_{k}\right\}$ is uniformly bounded then $d\left(z_{k+2}, z_{k+1}\right)<\infty ; k \in \mathbf{N}_{0}$.

(ii) Assume that the self-mappings on $X$ in the subsequence $\left\{T_{k}\right\}_{k \geq n_{0}}$ are contractive for some $n_{0} \in \mathbf{N}_{0}$, that the sequence of operators $\left\{T_{k}\right\}$ converges to $T: X \rightarrow X$, and that the projection operator $P: X \rightarrow M \subset$ $X$ is constant and bounded (i.e., if it is not orthogonal, i.e., it is oblique, then its norm exceeds one and it is finite) then Property (i) holds. Furthermore, $\exists \lim _{k \rightarrow \infty} d\left(z_{k+2}, z_{k+1}\right)=0$ and $\left\{z_{k+1}=P T_{k} x_{k}\right\}$ is a Cauchy sequence which converges to some unique limit point $z(=P T x) \in M$ for any initial iterate $x_{0} \in X$, where $x(=T x) \in X$ is the unique fixed point of $T$ : $X \rightarrow X$.

(iii) Assume that there is a strictly sequence of nonnegative integers $\left\{j_{k}\right\}$ such that the difference sequence $\left\{j_{k+1}-j_{k}\right\}$ is uniformly bounded and has a limit $J \in \mathbf{N}$ as $k \rightarrow$ $\infty$. Assume also that the associate sequence of composite self-mappings $\widehat{T}\left(j_{k+1}+1, j_{k}\right)=\left\{T_{j_{k+1}} \cdots T_{j_{k}+1} T_{j_{k}}\right\}$ is contractive and that the sequence projection operators $\left\{P_{k}\right\}$ from $X$ to the sequence of subspaces $\left\{M_{k}\right\}$ is uniformly bounded and has a set of subsequences each converging to a set $\left\{P_{j_{i}}\right\} \rightarrow \widehat{P}_{i}$ of projectors from $X$ to $\left\{M_{j_{i}}\right\}$. Then, $\exists \lim _{k \rightarrow \infty} d\left(z_{j_{k+1}+1}, z_{j_{k}+1}\right)=0$, and there is at most a finite number $J$ of distinct Cauchy subsequences $\left\{z_{j_{k}}\right\}$ with distinct limit points $\left\{\widehat{z}_{1}, \ldots, \widehat{z}_{J}\right\}$ in $X$.

Proof. Since the metric is homogeneous and translationinvariant then the complete metric space $(X, d)$ can also be considered as a Banach space $(X,\|\|)$ under the metricinduced norm defined as $\|x-y\|=d(x, y)$; for all $x, y \in$ $X$. The norm of any projection operator in the considered sequence is defined as $\left\|P_{k}\right\|=\sup _{\|x(\in X) \neq 0\| \leq 1}\left(\left\|P_{k} x\right\| /\|x\|\right)=$ $\sup _{\|x(\in X)\|=1}\left(\left\|P_{k} x\right\| /\|x\|\right)=\sup _{\|x(\in X)\|=1}\left\|P_{k} x\right\| ; k \in \mathbf{N}_{0}$. Then, if $\widehat{T}(k+1, j): X \rightarrow X$ is the left-composite self-mapping $\widehat{T}(k+1, j)=T_{k} \cdots T_{j+1} T_{j}$ for any $k(\geq j), j \in \mathbf{N}_{0}$, one gets from direct calculations, by using the property that the metric is homogeneous and translation-invariant, the following relations for any iterated sequences $\left\{x_{k}\right\}$ in $X$ and $\left\{z_{k}\right\}$ in $M_{k}$ constructed as $x_{k+1}=T_{k} x_{k}, z_{k}=P_{k} x_{k}$ with arbitrary $x_{0} \in X ; k \in \mathbf{N}$ :

$$
\begin{aligned}
& d\left(z_{k+2}, z_{k+1}\right) \\
& =d\left(P_{k+2} x_{k+2}, P_{k+1} x_{k+1}\right) \\
& =d\left(P_{k+1} x_{k+2}, P_{k+1} x_{k+1}+P_{k+1} x_{k+2}-P_{k+2} x_{k+2}\right) \\
& \leq d\left(P_{k+1} x_{k+2}, P_{k+1} x_{k+1}\right) \\
& \quad+d\left(P_{k+1} x_{k+1}, P_{k+1} x_{k+1}+P_{k+1} x_{k+2}-P_{k+2} x_{k+2}\right) \\
& \leq d\left(P_{k+1} x_{k+2}, P_{k+1} x_{k+1}\right)+d\left(P_{k+2} x_{k+2}, P_{k+1} x_{k+2}\right)
\end{aligned}
$$

$$
\begin{aligned}
= & \left\|P_{k+1} x_{k+2}-P_{k+1} x_{k+1}\right\|+\left\|P_{k+2} x_{k+2}-P_{k+1} x_{k+2}\right\| \\
\leq & \left\|P_{k+1}\right\|\left\|x_{k+2}-x_{k+1}\right\|+\left\|P_{k+2}-P_{k+1}\right\|\left\|x_{k+2}\right\| \\
= & \left\|P_{k+1}\right\| d\left(x_{k+1}, x_{k+2}\right)+\left\|P_{k+2}-P_{k+1}\right\| d\left(x_{k+2}, 0\right) \\
= & \left\|P_{k+1}\right\| d\left(T_{k} x_{k}, T_{k+1} T_{k} x_{k}\right) \\
& +\left\|P_{k+2}-P_{k+1}\right\| d\left(\widehat{T}(k+2,0) x_{0}, 0\right) \\
\leq & \left\|P_{k+1}\right\| d\left(x_{1}, x_{0}\right) \\
& +\left\|P_{k+2}-P_{k+1}\right\| d\left(\widehat{T}(k+2,0) x_{0}, 0\right) \\
\leq & \left\|P_{k+1}\right\| d\left(x_{1}, x_{0}\right)+\left(\left\|P_{k+1}\right\|+\left\|P_{k+2}\right\|\right) d\left(x_{0}, 0\right) \\
\leq & \left\|P_{k+1}\right\|\left(d\left(T_{0} x_{0}, 0\right)+d\left(x_{0}, 0\right)\right) \\
& +\left(\left\|P_{k+1}\right\|+\left\|P_{k+2}\right\|\right)\left\|x_{0}\right\| ; \quad k \in \mathbf{N}_{0}
\end{aligned}
$$

since the metric is homogeneous and translation-invariant, the norm is an induced-metric norm, then $\left\|x_{k}\right\|=d\left(x_{k}, 0\right)=$ $d\left(\widehat{T}(k, 0) x_{0}, 0\right)$, where $z_{k} \in M_{k}$, and the self-mappings in the sequence $\left\{T_{k}\right\}$ on $X$ are all non-expansive; $k \in \mathbf{N}_{0}$, and the sequence of projection operators $\left\{P_{k}\right\}$ from $X$ to the sequence of subspaces $\left\{M_{k}\right\}$ is uniformly bounded with $\sup _{k \in \mathbf{N}_{0}}\left\|P_{k}\right\| \leq$ $\mu<\infty$. Then, one has from (2)

$$
d\left(z_{k+2}, z_{k+1}\right) \leq 4 \mu\left\|x_{0}\right\|<\infty ; \quad k \in \mathbf{N}_{0},
$$

where $\mu=1$ if all the projections are orthogonal and $\mu>1$, otherwise. Hence, Property (i). If $P_{k}=P_{k+1}=P$ for $k \in \mathbf{N}_{0}$ is a constant bounded projection from $X$ to $M$ with $M_{k}=M \subset$ $X$ being constant for $k \in \mathbf{N}_{0}$ and all the self-mappings on $X$ of the sequence $\left\{T_{k}\right\}$ are contractive then one gets from (2) for the real constant $K=\sup _{k\left(\geq n_{0}\right) \in \mathbf{N}_{0}} K_{k}$ such that $K \in[0,1)$ that Property (i) holds according to the relation

$$
\begin{aligned}
& d\left(z_{k+2}, z_{k+1}\right) \\
& \leq\|P\| d\left(T_{k} x_{k}, T_{k+1} x_{k+1}\right) \\
& \leq\|P\| d\left(T_{k} x_{k}, T_{k} x_{k+1}+T_{k+1} x_{k+1}-T_{k} x_{k+1}\right) \\
& \leq\|P\| d\left(T_{k} x_{k}, T_{k} x_{k+1}\right) \\
&+\|P\| d\left(T_{k} x_{k+1}, T_{k} x_{k+1}+T_{k+1} x_{k+1}-T_{k} x_{k+1}\right) \\
&=\|P\|\left(d\left(T_{k} x_{k}, T_{k} x_{k+1}\right)+\|P\| d\left(0, T_{k+1} x_{k+1}-T_{k} x_{k+1}\right)\right) \\
&=\|P\|\left(d\left(T_{k} x_{k}, T_{k} x_{k+1}\right)+d\left(T_{k} x_{k+1}, T_{k+1} x_{k+1}\right)\right) \\
&=\|P\|\left(\left\|T_{k} x_{k}-T_{k} x_{k+1}\right\|+\left\|T_{k} x_{k+1}-T_{k+1} x_{k+1}\right\|\right) \\
& \leq\|P\|\left\|T_{k}\right\|\left\|x_{k}-x_{k+1}\right\|+\|P\|\left\|T_{k}-T_{k+1}\right\|\left\|x_{k+1}\right\|
\end{aligned}
$$




$$
\begin{aligned}
& \leq\|P\|\left(\left\|T_{k}\right\|\left\|x_{k}-x_{k+1}\right\|+\left\|T_{k}-T_{k+1}\right\|\right. \\
& \left.\quad \times d\left(\widehat{T}(k+1,0) x_{n_{0}}, \widehat{T}(k+1,0) 0\right)\right) \\
& \leq\|P\|\left(K^{k-n_{0}+1} d\left(x_{n_{0}+1}, x_{n_{0}}\right)\right. \\
& \left.+\frac{K\left(1-K^{k-n_{0}}\right)}{1-K}\left\|T_{k}-T_{k+1}\right\|\left\|x_{n_{0}}\right\|\right)<\infty ; \\
& \quad k\left(\geq n_{0}\right) \in \mathbf{N}_{0}
\end{aligned}
$$

so that $\exists \lim _{k \rightarrow \infty} d\left(z_{k+2}, z_{k+1}\right)=0$ from (4) for any initial value $x_{0} \in X$ of the iteration since $K^{k-n_{0}-1} \rightarrow 0$ and $\| T_{k}-$ $T_{k+1} \| \rightarrow 0$ as $k \rightarrow \infty$ since $\left\{T_{k}\right\} \rightarrow T$. Then, $\left\{z_{k}\right\}$ is Cauchy sequence which has a limit $z$ in $M$, since $M$ is closed, [4]. It is now proven that $z(\in M)=P x$ is the unique limit point in $M$ of any sequence of iterates, where $x(=T x) \in X$ is a fixed point of the self-mapping $T: X \rightarrow X$ which is unique from Banach contraction principle. It is now proven that $T: X \rightarrow X$ is contractive. Assume not so that one has if $T: X \rightarrow X$ is not contractive:

$$
\begin{aligned}
& d\left(x_{k+1}, x_{k}\right) \\
& \leq d\left(T x_{k+1}, T x_{k}\right) \\
&= d\left(T_{k} x_{k+1}, T_{k} x_{k}+T x_{k}-T_{k} x_{k}+T_{k} x_{k+1}-T x_{k+1}\right) \\
& \leq d\left(T_{k} x_{k+1}, T_{k} x_{k}\right) \\
&+d\left(T_{k} x_{k}, T_{k} x_{k}+T x_{k}-T_{k} x_{k}+T_{k} x_{k+1}-T x_{k+1}\right) \\
&= d\left(T_{k} x_{k+1}, T_{k} x_{k}\right)+d\left(0, T x_{k}-T_{k} x_{k}+T_{k} x_{k+1}-T x_{k+1}\right) \\
&= d\left(T_{k} x_{k+1}, T_{k} x_{k}\right)+d\left(T_{k} x_{k}+T x_{k+1}, T x_{k}+T_{k} x_{k+1}\right) \\
& \leq d\left(T_{k} x_{k+1}, T_{k} x_{k}\right)+\left\|T_{k}-T\right\|\left(\left\|x_{k}\right\|+\left\|x_{k+1}\right\|\right) \\
& \leq K_{k} d\left(x_{k+1}, x_{k}\right)+\left\|T_{k}-T\right\|\left(\left\|x_{k}\right\|+\left\|x_{k+1}\right\|\right) ;
\end{aligned}
$$

for nonzero $x_{k}$ and $x_{k+1}$ since $T_{k}: X \rightarrow X$ is contractive for $k \geq n_{0}$. Then, one gets, since $\left\|T_{k}-T\right\| \rightarrow 0$ as $k \rightarrow \infty$, that

$$
\begin{gathered}
\limsup _{k \rightarrow \infty}\left[\left(1-K_{k}-\left\|T_{k}-T\right\|\right)\left(\left\|x_{k}\right\|+\left\|x_{k+1}\right\|\right)\right] \\
\quad=\limsup _{k \rightarrow \infty}\left[\left(1-K_{k}\right)\left(\left\|x_{k}\right\|+\left\|x_{k+1}\right\|\right)\right] \leq 0
\end{gathered}
$$

which is a contradiction since $K_{k}<1$ for $k \geq n_{0}$ unless $\left\{x_{k}\right\}$ converges to zero. If $\left\{x_{k}\right\}$ converges to zero then there are $n_{1}(\geq$ $\left.n_{0}\right) \in \mathbf{N}_{0}$ and $0<\lambda=\lambda\left(n_{1}\right)<1-\sup _{k \geq n_{1}} K_{k}$ such that $\left\|T_{k}-T\right\| \leq \lambda$ for all $k \geq n_{1}$ since $\left\|T_{k}-T\right\| \rightarrow 0$ as $k \rightarrow \infty$ and some $k_{1} \geq n_{1}$ such that $\left\|x_{k_{1}}\right\|+\left\|x_{k_{1}+1}\right\|>0$ that yields the contradiction

$$
0<\left(1-K_{k_{1}}-\lambda\right)\left(\left\|x_{k_{1}}\right\|+\left\|x_{k_{1}+1}\right\|\right) \leq 0 .
$$

Thus, if the subsequence $\left\{T_{k}\right\}_{k \geq n_{0}}$ is contractive in $X$ then its $\operatorname{limit} T: X \rightarrow X$ is also contractive. Now, since $T: X \rightarrow X$ is contractive then its fixed point is unique since $(X, d)$ is complete. It is clear that $z=P T x$ is a limit point in $M$ of any iterated sequence. Assume that it is not unique so that there are two limit points $z=P T x, \widehat{z}=P T \widehat{x}(\neq z) \in M$ for some $\widehat{x}(\neq x) \in X$ which is not trivially a fixed point of $T: X \rightarrow X$ (since the fixed point $x \in X$ of the contractive self-mapping $T: X \rightarrow X$ is unique if $(X, d)$ is complete). Thus, from Banach contraction principle and since $(X, d)$ is complete, one has

$$
\begin{aligned}
0 \longleftarrow d\left(P T_{k} \hat{x}, P T_{k} x\right) & =\left\|P T_{k} \hat{x}-P T_{k} x\right\| \\
& \leq\|P\|\left\|T_{k} \widehat{x}-T_{k} x\right\| \\
& \leq\|P\| K^{k} d(\widehat{x}, x)<\infty ; \\
k & \in \mathbf{N}_{0}
\end{aligned}
$$

as $k \rightarrow \infty$ since $\left\{T_{k}\right\}$ converges, there is a limit self-mapping $T$ on $X$ :

$$
\widehat{z} \longleftarrow P T_{k} \widehat{x} \longrightarrow P T_{k} x \longrightarrow P T x=P x=z .
$$

Thus, $P T_{k} x \rightarrow \widehat{z}=z$ as $k \rightarrow \infty$. Hence a contradiction to $\widehat{z} \neq z$ and then $z$ in $M$ is the unique limit point of $P T: X \rightarrow$ $M$ even in the event that there is $\widehat{x}(\neq x=T x) \in X$ such that $P T \widehat{x}=P T x=P x=z$. Property (ii) has been proven.

On the other hand, if the sequence of operators is uniformly bounded then $\sup _{k \in \mathrm{N}_{0}}\left\|P_{k}\right\| \leq \mu<\infty$ and, if furthermore, the sequence of compositie mappings $\left\{\widehat{T}\left(j_{k+1}, j_{k}\right)\right\}$ is contractive with some constant $\widehat{K} \in[0,1)$ given by $\widehat{K}=$ $\sup _{k \in \mathbf{N}_{0}}\left(\prod_{j=j_{k}}^{j_{k+1}-1}\left[K_{j}\right]\right), k \in \mathbf{N}_{0}$, where $\left\{j_{k}\right\}$ is a strictly increasing sequence of natural numbers such that the sequence $\left\{j_{k+1}-j_{k}\right\}$ is uniformly bounded, one has directly from (1)-(2):

$$
\begin{aligned}
d\left(z_{j_{k+1}}, z_{j_{k}}\right) & \leq \mu d\left(x_{j_{k}}, \widehat{T}\left(j_{k+1}, j_{k}\right) x_{j_{k}}\right) \\
& \leq \mu\left(\widehat{K}^{j_{k}}\left[d\left(x_{1}, x_{0}\right)+2\left\|x_{0}\right\|\right]\right)<\infty ;
\end{aligned}
$$

$$
\begin{aligned}
d\left(z_{j_{k}+i_{k}}, z_{j_{k}}\right) & \leq \mu d\left(x_{j_{k}}, \widehat{T}\left(j_{k+1}, j_{k}\right) x_{j_{k}}\right) \\
& \leq \mu\left(\prod_{j=j_{k}}^{j_{k}+i_{k}-1} K_{j}\right)\left(\widehat{K}^{j_{k}}\left[d\left(x_{1}, x_{0}\right)+2\left\|x_{0}\right\|\right]\right) \\
& <\infty
\end{aligned}
$$

for $k \in \mathbf{N}_{0}$, where $\left\{\left\{i_{k}\right\}\right\}$ is a sequence of finite sets of natural numbers satisfying $j \in\left\{i_{k}\right\} \Leftrightarrow 1 \leq j<\left(j_{k+1}-j_{k}\right)+1$ for $k \in$ $\mathbf{N}_{0}$. Thus, one gets from (10):

$$
\exists \lim _{j_{k} \rightarrow \infty} d\left(z_{j_{k+1}}, z_{j_{k}}\right)=\lim _{j_{k} \rightarrow \infty} d\left(z_{j_{k+1}+j}, z_{j_{k}}\right)=0
$$

for any $j \in\left\{i_{k}\right\}$ since $j_{k} \rightarrow \infty$ as $k \rightarrow \infty$ and. Since $\left\{j_{k+1}-j_{k}\right\}$ is uniformly bounded with existing limit $J \in \mathbf{N}$ as 
$k \rightarrow \infty, \widehat{T}\left(j_{k+1}+1, j_{k}\right)=\left\{T_{j_{k+1}} \cdots T_{j_{k}+1} T_{j_{k}}\right\}$ is contractive and the projection sequence $\left\{P_{k}\right\}$ from $X$ to the sequence of subspaces $\left\{M_{k}\right\}$ is uniformly bounded while having a finite set of subsequences $\left\{P_{j_{i}}\right\}$ converging to a set $P_{j_{i}} \rightarrow \widehat{P}_{i}$ of projectors from $X$ to $\left\{M_{k}\right\}$ for $i \in \bar{J}$ then

$$
\begin{aligned}
& \exists \lim _{k \rightarrow \infty} d\left(z_{j_{k+1}+1}, z_{j_{k}+1}\right) \\
& \quad=\lim _{k \rightarrow \infty} d\left(P_{j_{k+1}+1} \widehat{T}\left(j_{k+1}+1,0\right) x_{0}, P_{j_{k}} \widehat{T}\left(j_{k}+1,0\right) x_{0}=0\right)
\end{aligned}
$$

so that $\left\{z_{j_{k+1}+1}=P_{j_{k+1}} \widehat{T}\left(j_{k+1}+1,0\right) x_{0}\right\}$ is a Cauchy sequence satisfying:

$$
\begin{array}{r}
z_{j_{k}+i} \longrightarrow \widehat{z}_{i}=\widehat{P}_{i}\left(\lim _{k \rightarrow \infty}\left(T_{j_{k}+i} \cdots T_{j_{k+i}-1} T_{j_{k}}\right) \widehat{z}_{i-1}\right) \\
\text { as } j_{i} \longrightarrow \infty, \quad i \in \bar{M} ; \widehat{z}_{i} \in\left(X \cap \bigcap_{k=0}^{\infty} M_{j_{k}+i-1}\right)
\end{array}
$$

for at most $J$ distinct points $\left\{\widehat{z}_{1}, \ldots, \widehat{z}_{J}\right\}$ since, by hypothesis, there is a natural number $J$ satisfying $\infty>J=\lim _{k \in \mathbf{N}_{0}}\left\{j_{k+1}-\right.$ $\left.j_{k}\right\} \geq 1$ and since $\left\{P_{j_{i}}\right\} \rightarrow \widehat{P}_{i} ; i \in \bar{J}$. Hence, Property (iii) holds.

Remark 2. The existence of some $\widehat{x}(\neq x=T x) \in X$ in the proof of Theorem 1(ii) often happens. For instance if $P T$ : $X \rightarrow M$ is linear then $\hat{x}=x+x_{a}$ fulfils the relations $P T x=P x=P T \widehat{x}=z$ for any $x_{a} \in \operatorname{Ker} P T$.

The following auxiliary result to be then used holds.

Lemma 3. Assume that the sequences of linear self-mappings $\left\{T_{n}\right\}$ and $\left\{P_{n}\right\}$ converge to respective limits $P$ and $T$ being mappings from $X$ to $M \subset X$ and from $X$ to $X$, respectively, in the sense that $P_{n} T_{n} x \rightarrow P$ T $x$ as $n \rightarrow \infty$ from any $x \in X$. Let $(X,\|\|)$ be a Banach space with the norm of any $Q: X \rightarrow X$ being defined by $\|Q\|=\sup _{x \in X,\|x\|=1}\|Q x\|$. For any given $\delta \in \mathbf{R}_{+}, \exists n_{0}=n_{0}(\delta)$ such that $\left\|P_{n} T_{n}\right\| \leq p t+\delta$, where $p=\|P\|$ and $t=\|T\|$. If $P T: X \rightarrow X$ is contractive then the sequence $\left\{P_{n} T_{n}\right\}$ of mappings from $X$ to $X$ is then asymptotically contractive.

Proof. Direct calculations yield

$$
\begin{aligned}
\left\|P_{n} T_{n}\right\|= & \sup _{\|x\|=1}\left\|P T x+P\left(T_{n}-T\right) x+\left(P_{n}-P\right) T_{n} x\right\| \\
\leq & \|P T\|+\|P\|\left\|T_{n}-T\right\|+\left\|P_{n}-P\right\|\left\|T_{n}\right\| \\
\leq & \|P T\|+\|P\|\left\|T_{n}-T\right\| \\
& +\left\|P_{n}-P\right\|\|T\|+\left\|P_{n}-P\right\|\left\|T_{n}-T\right\|
\end{aligned}
$$

and for any given $\varepsilon \in \mathbf{R}_{+}$, there are $n_{i}=n_{i}(\varepsilon) \in \mathbf{N}_{0}$ for $i=1,2$ such that $\left\|T_{n}-T\right\|<\varepsilon$ for all integer $n>n_{1}$ and $\left\|P_{n}-P\right\|<\varepsilon$ for all integer $n>n_{2}$. Thus, if $n_{3}=\max \left(n_{1}, n_{2}\right)$ then one has for any $n>n_{3}$ :

$$
\begin{aligned}
\left\|P_{n} T_{n}\right\| & \leq\|P T\|+(\|P\|+\|T\|+\varepsilon) \varepsilon \\
& =p t+(p+t+\varepsilon) \varepsilon \leq p t+\delta .
\end{aligned}
$$

The last inequality holds if and only if $\varepsilon^{2}+(p+t) \varepsilon-\delta \leq 0$ for any given positive real constant $\delta$ and any positive real constant $\varepsilon=\varepsilon(\delta)$ being sufficiently small to satisfy $\varepsilon \leq$ $(1 / 2)\left(\sqrt{(p+t)^{2}+4 \delta}-p-t\right) \leq \sqrt{\delta} / 2$. Since $\left\|P_{n}\right\| \rightarrow p$ and $\left\|T_{n}\right\| \rightarrow t$, there are finite natural numbers $n_{1}=$ $n_{1}(\delta, \varepsilon)=n_{1}(\varepsilon), n_{2}=n_{2}(\delta, \varepsilon)=n_{2}(\varepsilon)$ such that $\varepsilon$ satisfies that constraint $\left\|P_{n} T_{n}\right\| \leq p t+\delta$ for any integer $n>n_{3}=$ $n_{3}(\delta, \varepsilon)=n_{3}(\varepsilon)>\max \left(n_{1}, n_{2}\right)$. If $P T: X \rightarrow X$ is contractive then $p t \leq K<1$ for some real constant $K$. Thus, there is $n_{3}=n_{3}(\varepsilon)$ such that $p t \leq K \leq\left\|P_{n} T_{n}\right\|<K_{1}<1$ for any given real $\delta<K_{1}-K$ and $\varepsilon \leq(1 / 2)\left(\sqrt{(p+t)^{2}+4 \delta}-p-\right.$ $t) \leq(1 / 2)\left(\sqrt{(p+t)^{2}+4\left(K_{1}-K\right)}-p-t\right) \leq \sqrt{K_{1}-K} / 2$ and then the sequence $\left\{P_{n} T_{n}\right\}$ is asymptotically contractive.

Note that Lemma 3 holds irrespective of the fact that one of the operators be a projection.

\section{Results on Contractive Mappings of Sequences of Composite Bounded Operators}

The results of Theorem 1 are now extended to the study of contractive compositions of linear operators belonging to two sequences of bounded operators $\left\{T_{k i}\right\}$ with $T_{i k}: \operatorname{Dom}\left(T_{i k}\right) \subset$ $X \rightarrow \operatorname{Im}\left(T_{i k}\right) \subset X$ to $X ; i=1,2$ so that none of them is necessarily a projection on some subspace of $X$. Some preparatory results are first established. In the following, a $\operatorname{Banach} \operatorname{space}(X,\|\|)$, being equivalent to a complete metric space $(X, d)$ with a homogeneous and translation-invariant metric induced-norm $d: X \times X \rightarrow \mathbf{R}_{0+}$ is considered such that $\|x\|=d(x, 0)=d(x+\alpha y, \alpha y)$ for any real $\alpha$ and any $x, y \in$ $X$. The subsequent result refers to the asymptotic distances in sequences involving a convergent composite sequence of bounded linear operators.

Lemma 4. Consider a Banach space $(X,\|\|)$, with $0 \in X$, being equivalent to a complete metric space $(X, d)$ with a homogeneous and translation-invariant metric induced-norm $d: X \times X \rightarrow \mathbf{R}_{0+}$. Consider also a composite sequence of two sequences of bounded linear operators $\left\{T_{k}=T_{2 k} T_{1 k}\right\}$ defined by $T_{k}: \operatorname{Dom}\left(T_{k}\right) \subset X \rightarrow \operatorname{Im}\left(T_{k}\right) \subset X$ defined by $T_{k} x=T_{2 k}\left(T_{1 k} x\right)=T_{2 k} T_{1 k} x$ for any $x \in \operatorname{Dom}\left(T_{k}\right)$, where $T_{i k}: \operatorname{Dom}\left(T_{i k}\right) \subset X \rightarrow \operatorname{Im}\left(T_{i k}\right) \subset X ; i=1,2$, provided that $\operatorname{Im}\left(T_{1 k}\right)(\neq \emptyset) \subset \operatorname{Dom}\left(T_{2 k}\right)$ and $\operatorname{Im}\left(T_{2 k}\right) \cap$ $\operatorname{Dom}\left(T_{1 k+1}\right) \neq \emptyset$; for all $k \in \mathbf{N}_{0}$. The following properties hold.

(i) Assume that $\left\{T_{i k}\right\} \rightarrow T_{i}(i=1,2)$. Then, $\lim _{k \rightarrow \infty} d$ $\left(T_{k} x, T_{2} T_{1} x\right)=0$; for all $x \in \operatorname{Dom}\left(T_{k}\right)$; for all $k \in$ $\mathbf{N}_{0}$.

(ii) Assume that $\left\{T_{1 k}\right\} \rightarrow T_{1}(i=1,2)$. Then, $\lim _{k \rightarrow \infty} d$ $\left(T_{k} x, T_{2 k} T_{1} x\right)=0$; for all $x \in \operatorname{Dom}\left(T_{k}\right)$; for all $k \in$ $\mathbf{N}_{0}$.

(iii) Assume that $\left\{T_{2 k}\right\} \rightarrow T_{2}(i=1,2)$. Then, $\lim _{k \rightarrow \infty} d$ $\left(T_{k} x, T_{2} T_{1 k} x\right)=0$; for all $x \in \operatorname{Dom}\left(T_{k}\right)$; for all $k \in$ $\mathbf{N}_{0}$.

(iv) Define the operator composite sequence $\{\widehat{T}(k+i+$ $1, k)\}$ of operators as $\widehat{T}(k+i+1, k)=T_{k+i} \cdots T_{k+1} T_{k}$ 
with $T_{k}=T_{j_{k} k} T_{j_{k}-1, k} \cdots T_{2 k} T_{1 k} ;$ for all $i, k \in \mathbf{N}_{0}$ subject to $\operatorname{Im}\left(T_{j k}\right)(\neq \emptyset) \subset \operatorname{Dom}\left(T_{j+1, k}\right)$ for $j \in$ $\overline{j_{k}}, \operatorname{Im} T_{j_{k} k}(\neq \emptyset) \subset \operatorname{Dom} T_{1, k+1}$ and $1 \leq j_{k} \leq J(\epsilon$ $\mathbf{N}_{0}$ ) < $\infty$; for all $k \in \mathbf{N}_{0}$. Define also the operator composite sequence of operators $\left\{\widehat{T}^{0}(k+i+1, k)\right\}$ as

$$
\begin{aligned}
& \widehat{T}^{0}(k+i+1, k)=T_{k+i}^{0} \cdots T_{k+1}^{0} T_{k}^{0} \\
& \quad=\left(T_{j_{k+i} k+i}^{0} \cdots T_{j_{k+i}-1, k+i}^{0} T_{1, k+i}^{0}\right) \cdots\left(T_{j_{k} k}^{0} \cdots T_{2 k}^{0} T_{1 k}^{0}\right)
\end{aligned}
$$

for $i, k \in \mathbf{N}_{0}$, where $T_{j k}^{0}=T_{j k}$ if $T_{j k}$ has not a limit as $k \rightarrow \infty$ and $T_{j k}^{0}=T_{j \infty}$ if $T_{j \infty}=\lim _{k \rightarrow \infty} T_{j k}$. Then

$$
\lim _{k \rightarrow \infty} d\left(\widehat{T}(k+i+1, i) x, \widehat{T}^{0}(k+i+1, i) x\right)=0 ;
$$

$$
\forall x \in \operatorname{Dom}\left(T_{10}\right), \forall i \in \mathbf{N}_{0} .
$$

Properties (i)-(iii) hold for any $x \in \operatorname{Dom}\left(T_{10}\right)$.

Proof. Assume that $\left\{T_{i k}\right\} \rightarrow T_{i}$ with $T_{i}: X \rightarrow X(i=$ $1,2)$ since $(X, d)$, equivalently $(X,\|\|)$, is complete so that $T_{i k} x \rightarrow T_{i} x(\in X)$ strongly for $i=1,2$ as $k \rightarrow$ $\infty$ for any $x \in \operatorname{Dom}\left(T_{10}\right)$ since $\operatorname{Im}\left(T_{1 k}\right)(\neq \emptyset) \subset$ Dom $\left(T_{2 k}\right)$ and $\operatorname{Im}\left(T_{2 k}\right) \cap \operatorname{Dom}\left(T_{1 k+1}\right) \neq \emptyset$; for all $k \in \mathbf{N}_{0}$. Then, $\lim _{k \rightarrow \infty} d\left(T_{k} x, T_{2} T_{1 k} x\right)=0$; for all $x \in \operatorname{Dom}\left(T_{10}\right)$, and

$$
\begin{aligned}
T_{k} x & =T_{2 k} T_{1 k} x=T_{2 k} T_{1} x+T_{2 k}\left(T_{1 k}-T_{1}\right) x \\
& =T_{2} T_{1} x+\left(T_{2 k}-T_{2}\right) T_{1} x+T_{2 k}\left(T_{1 k}-T_{1}\right) x
\end{aligned}
$$

that leads to

$$
\begin{aligned}
&\left\|\left(T_{k}-T_{2} T_{1}\right) x\right\| \leq\left\|\left(T_{2 k}-T_{2}\right) T_{1} x\right\|+\left\|T_{2 k}\left(T_{1 k}-T_{1}\right) x\right\| \\
& \Longrightarrow \exists \lim _{k \rightarrow \infty}\left(T_{k}-T_{2} T_{1}\right) x \\
&=\lim _{k \rightarrow \infty} d\left(\left(T_{k}-T_{2} T_{1}\right) x, 0\right) \\
&=\lim _{k \rightarrow \infty} d\left(T_{k} x, T_{2} T_{1} x\right)=0 ; \\
& \forall x \in \operatorname{Dom}\left(T_{10}\right) .
\end{aligned}
$$

Hence, Property (i). Now, assume that only $\left\{T_{1 k}\right\}$ has a limit. Then,

$$
\begin{aligned}
T_{k} x & =T_{2 k} T_{1 k} x \\
& =T_{2 k} T_{1} x+T_{2 k}\left(T_{1 k}-T_{1}\right) x \\
& \Longrightarrow\left\|\left(T_{k}-T_{2 k} T_{1}\right) x\right\| \\
& \leq\left\|T_{2 k}\left(T_{1 k}-T_{1}\right) x\right\| ; \quad \forall x \in \operatorname{Dom}\left(T_{k}\right), \\
& \exists \lim _{k \rightarrow \infty}\left(T_{k}-T_{2 k} T_{1}\right) x \\
& =\lim _{k \rightarrow \infty} d\left(\left(T_{k}-T_{2 k} T_{1}\right) x, 0\right) \\
& =\lim _{k \rightarrow \infty} d\left(T_{k} x, T_{2 k} T_{1} x\right)=0 ; \quad \forall x \in \operatorname{Dom}\left(T_{k}\right) .
\end{aligned}
$$

Hence, Property (ii). Finally, assume that only $\left\{T_{2 k}\right\}$ has a limit. Then,

$$
\begin{aligned}
T_{k} x= & T_{2 k} T_{1 k} x \\
= & T_{2} T_{1 k} x+\left(T_{2 k}-T_{2}\right) T_{1 k} x \\
& \Longrightarrow \\
\leq & \left\|\left(T_{k}-T_{2} T_{1 k}\right) x\right\| \\
& \forall x \in \operatorname{Dom}\left(T_{k}\right), \\
\exists & \lim _{k \rightarrow \infty}\left(T_{k}-T_{2} T_{1 k}\right) x \\
= & \lim _{k \rightarrow \infty} d\left(\left(T_{k}-T_{2} T_{1 k}\right) x, 0\right) \\
= & \lim _{k \rightarrow \infty} d\left(T_{k} x, T_{2} T_{1 k} x\right)=0 ;
\end{aligned}
$$

Hence, Property (iii).

Property (iv) is direct from Properties (i)-(iii) and the associative property of composition of operators since for any $k \in \mathbf{N}_{0+}, T_{k} x$ exists in $\operatorname{Im}\left(T_{k}\right)$ if $\operatorname{Im}\left(T_{1 k}\right) \subset$ Dom $\left(T_{2 k}\right)$ and $\operatorname{Dom}\left(T_{1 k+1}\right) \supset \operatorname{Im}\left(T_{2 k}\right)$ for $x \in \operatorname{Dom}\left(T_{10}\right)$, and then, $\operatorname{Dom}\left(T_{k}\right) \subset \operatorname{Dom}\left(T_{1 k}\right)$ and $\operatorname{Im}\left(T_{k}\right) \supset \operatorname{Im}\left(T_{2 k}\right)$; for all $k \in$ $\mathbf{N}_{0}$ since

$$
\begin{aligned}
& \widehat{T}(k+i+1, k)=T_{k+i} \cdots T_{k+1} T_{k} \\
& \quad=\left(T_{j_{k+i} k+i} \cdots T_{j_{k+i}-1, k+i} T_{1, k+i}\right) \cdots\left(T_{j_{k} k} \cdots T_{2 k} T_{1 k}\right) ;
\end{aligned}
$$

$\forall k \in \mathbf{N}_{0}$.

Then, for any finite $i \in \mathbf{N}$, one gets

$$
\begin{aligned}
& \left\|\widehat{T}(k+i+1, k)-\widehat{T}^{0}(k+i+1, k)\right\| \\
& \leq \sum_{j=k}^{k+i} c_{j}\left[o\left(\left\|T_{j}^{0}-T_{j}\right\|\right)\right] \leq \sum_{j=k}^{k+i} \sum_{\ell_{j}=1}^{j_{k}} c_{j \ell_{j}}\left[o\left(\left\|T_{\ell_{j} j}^{0}-T_{\ell_{j} j}\right\|\right)\right] \\
& \quad \longrightarrow 0 \text { as } k \longrightarrow \infty
\end{aligned}
$$

for some positive finite constants $c_{j}$ and $c_{j \ell_{j}}$ since any linear operator $T_{\ell_{j} j}^{0}$ with a limit $T_{\ell_{\infty} j}$ admits a unique decomposition $T_{\ell_{j} j}^{0}=T_{\ell_{\infty} j}+\widetilde{T}_{l_{j} j}$, with $\widetilde{T}_{l_{j} j} \rightarrow 0$ as $k \rightarrow \infty$, for all $\ell_{j} \epsilon$ $\bar{j}_{k}, j=1,2, \ldots, k+i$.

The next result is concerned with the closeness of the limit operator if the sequence of operators is closed.

Lemma 5. Consider a sequence of closed linear operators $\left\{T_{n}\right\}$ defined by $T_{n}: \operatorname{Dom}\left(T_{n}\right) \subset X \rightarrow \operatorname{Im}\left(T_{n}\right) \subset X$ in a Banach space $(X,\|\|)$, such that $\operatorname{Im}\left(T_{n}\right) \subset \operatorname{Dom}\left(T_{n+1}\right)$ with $\operatorname{Im}\left(T_{n}\right) \cap \operatorname{Dom}\left(T_{n+1}\right) \neq \emptyset$, which converge to a limit operator $T: \operatorname{Dom}(T) \subset X \rightarrow \operatorname{Im}(T) \subset X$. Then, such a limit is a closed operator which is bounded if all the operators of the sequence are bounded. 
Proof. Note the following:

(1) $\left\{T_{n} x_{m}^{(n)}\right\} \rightarrow T x_{m}^{(n)}$ as $n, m \rightarrow \infty$ for any bounded sequence $\left\{x_{m}^{(n)}\right\} \subset \operatorname{Dom}\left(T_{n}\right)$ since $\exists \lim _{n, m \rightarrow \infty} \|\left(T_{n}-\right.$ $T) x_{m}^{(n)}\left\|\leq \lim _{n, m \rightarrow \infty}\right\| T_{n}-T\|\| x_{m}^{(n)} \|=0$ since $\left\{T_{n}\right\} \rightarrow$ $T$. Furthermore,

$$
\begin{aligned}
\|T x\| & \leq\left\|T_{n} x\right\|+\left\|\left(T_{n}-T\right) x\right\| \leq\left\|K_{n}+\widetilde{K}_{n}\right\|\|x\| \\
& \leq\left\|K_{n}\right\|\|x\|+\left\|\widetilde{K}_{n}\right\|\|x\| ; \quad \forall x \in X
\end{aligned}
$$

for any $n \in \mathbf{N}_{0}, K_{n} \geq\left\|T_{n}\right\|$ is a finite real sequence of constants $\left\{K_{n}\right\}$ with $K_{n} \leq \bar{K}$ for any $n \in \mathbf{N}_{0}$, since $\left\{\left\|T_{n}\right\|\right\}$ is convergent, and $\widetilde{K}_{n} \geq\left\|T_{n}-T\right\|$; for all $n \in$ $\mathbf{N}_{0}$. Again, since $\left\{\left\|T_{n}\right\|\right\}$ is convergent, there is $n_{0} \in \mathbf{N}$ such that $\widetilde{K} \geq\left\|\widetilde{K}_{n}\right\|$ for any $n\left(\geq n_{0}\right) \in \mathbf{N}_{0}$, $\|T x\| \leq$ $\left\|K_{n}\right\|\|x\|+\left\|\widetilde{K}_{n}\right\|\|x\| \leq(K+\widetilde{K})\|x\|$ so that $T: X \rightarrow X$ is bounded.

(2) If the bounded sequence $\left\{x_{m}^{(n)}\right\} \subset \operatorname{Dom}\left(T_{n}\right)$ converges to $x^{(n)} \subset \operatorname{Dom}\left(T_{n}\right)$ for any $n \in \mathbf{N}_{0}$ then $\left\{T_{n} x_{m}^{(n)}\right\} \rightarrow$ $T_{n} x^{(n)}$ for any $n \in \mathbf{N}_{0}$ as $m \rightarrow \infty$ since $\left\{T_{n}\right\}$ is a closed operator for any $n \in \mathbf{N}_{0}$ so that

$$
\begin{aligned}
\exists \lim _{m \rightarrow \infty}\left\|T_{n} x_{m}^{(n)}-T_{n} x^{(n)}\right\| & \leq \lim _{m \rightarrow \infty}\left\|T_{n}\left(x_{m}^{(n)}-x^{(n)}\right)\right\| \\
& \leq\left\|T_{n}\right\| \lim _{m \rightarrow \infty}\left\|x_{m}^{(n)}-x^{(n)}\right\|=0 .
\end{aligned}
$$

(3) One gets combining the above points (1)-(2) that: $\left\{T_{n} x_{m}^{(n)}\right\} \rightarrow T_{n} x^{(n)} \rightarrow T x_{m}^{(n)} \rightarrow T x$ as $n, m \rightarrow$ $\infty$ if $\left\{x_{m}^{(n)}\right\} \rightarrow x^{(n)} \rightarrow x$ for any $n \in \mathbf{N}_{0}$ where $\left\{x_{m}^{(n)}\right\} \rightarrow\left\{x^{(n)}\right\} \subset \operatorname{Dom}\left(T_{n}\right)$ as $m \rightarrow \infty$, and then $\left\{x_{m}^{(n)}\right\} \rightarrow\left\{x^{(n)}\right\} \in \operatorname{Dom}\left(T_{n}\right)$ as $m \rightarrow \infty$ for any $n \in$ $\mathbf{N}_{0}$ and $\left\{x_{m}^{(n)}\right\} \rightarrow\left\{x^{(n)}\right\} \rightarrow x \in \operatorname{Dom}(T)$ as $n, m \rightarrow$ $\infty$ since $\left\{T_{n}\right\}$ is a sequence of closed operators which converges. Thus, the limit of bounded converging sequences belongs to the domain of the limit operator. Furthermore, one has for any bounded sequence $\left\{x_{n}\right\}$ converging to $x \in \operatorname{Dom}(T)$ :

$$
\begin{aligned}
\left\|T_{n} x_{n}-T x\right\| & =\left\|T x_{n}+\left(T_{n}-T\right) x_{n}-T x\right\| \\
& \leq\|T\|\left\|x_{n}-x\right\|+\left\|T_{n}-T\right\|\left\|x_{n}\right\| \longrightarrow 0
\end{aligned}
$$

as $k \rightarrow \infty$ then $T_{n} x_{n} \rightarrow T x$ strongly so that $T: \operatorname{Dom}(T) \subset$ $X \rightarrow \operatorname{Im}(T) \subset X$ is a closed operator as a result.

The above result can be extended to sequences of operators not all of them being bounded provided that each of such sequences of operators can be decomposed as a composition of subsequences of composite operators such that each of such a composite subsequence is bounded. The above result can be applied to sequences of operators not all of them being bounded. It is well-known that a sequence of linear operators on a Hilbert space $[5,6]$ is bounded if and only if they are closed and their domain is the whole vector space $X,[1,4]$. Thus, we have the following result using Lemma 5.
Lemma 6. Consider a sequence of linear bounded operators $\left\{T_{n}\right\}$ defined by $T_{n}: X \rightarrow X$ in a Banach space $(X,\|\|)$ which converge to a limit operator $T: X \rightarrow X$. Then, such a limit is a bounded linear closed operator.

Proof. Since the operators are all bounded then their domain is $X$, their range is in $X$ and are all closed. The conditions of Lemma 5 hold with

$$
\begin{aligned}
X \equiv & \operatorname{Im}\left(T_{n}\right) \subset X \equiv \operatorname{Dom}\left(T_{n+1}\right) \\
& \text { with } \operatorname{Im}\left(T_{n}\right) \cap \operatorname{Dom}\left(T_{n+1}\right)=X \neq \emptyset .
\end{aligned}
$$

Then, the limit $T: X \rightarrow X$ of $\left\{T_{n}\right\}$ is also bounded and closed from Lemma 5.

The subsequent result is concerned with the limit operator of a sequence of linear operators being compact if all the operators in the sequence are bounded and at least one of them is compact.

Lemma 7. The following properties hold.

(i) Consider a sequence of bounded compact linear operators $\left\{T_{n}\right\}$ defined by $T_{n}: \operatorname{Dom}\left(T_{k}\right) \subset X \rightarrow$ $\operatorname{Im}\left(T_{n}\right) \subset X$ in a Banach space $(X,\|\|)$, such that $\operatorname{Im}\left(T_{n}\right) \subset \operatorname{Dom}\left(T_{n+1}\right)$ with $\operatorname{Im}\left(T_{n}\right) \cap \operatorname{Dom}\left(T_{n+1}\right) \neq \emptyset$, which converge to a limit operator $T: \operatorname{Dom}(T) \subset X \rightarrow$ $\operatorname{Im}(T) \subset X$. Then, such a limit is a compact operator.

(ii) Assume that the sequence $\left\{T_{n}\right\}$ of bounded operators satisfies that there is at least one compact operator within all subsequences $\left\{T_{j_{n}}, T_{j_{n}+1}, \ldots, T_{j_{n+1}-1}\right\}$ being subject to $\max _{n \in \mathbf{N}_{0}}\left(j_{n+1}-j_{n}\right) \leq c_{j}<\infty$ for some subsequence $\left\{j_{n}\right\} \subset \mathbf{N}_{0}$ for any $n \in \mathbf{N}_{0}$. Then, the composed operator $\widehat{T}(n, m)$ is compact as it is its limit provided that it exists.

Proof. We have to prove that if $\left\{x_{n}\right\}$ is bounded then $\left\{T x_{n}\right\}$ is convergent. Note that for given bounded sequences $\left\{x_{n}^{(i)}\right\}$ and $\left\{x_{n}^{(j)}\right\} ; i, j, n \in \mathbf{N}_{0}$ that

$$
\begin{aligned}
& \left\|T x_{n}^{(i)}-T x_{n}^{(j)}\right\| \\
& \quad=\left\|\left(T-T_{n}\right) x_{n}^{(i)}+T_{n} x_{n}^{(i)}-T_{n} x_{n}^{(j)}-\left(T-T_{n}\right) x_{n}^{(j)}\right\| \\
& \quad \leq\left\|\left(T-T_{n}\right) x_{n}^{(i)}\right\|+\left\|\left(T-T_{n}\right) x_{n}^{(j)}\right\|+\left\|T_{n}\right\|\left\|x_{n}^{(i)}-x_{n}^{(j)}\right\|
\end{aligned}
$$

and, one gets by taking subsequences $\left\{z_{i}\right\} \subset\left\{x_{n}^{(i)}\right\},\left\{z_{j}\right\} \subset$ $\left\{x_{n}^{(j)}\right\}$

$$
\left\|T z_{i}-T z_{j}\right\| \leq\left\|T-T_{n}\right\|\left(\left\|z_{i}\right\|+\left\|z_{j}\right\|\right)+\left\|T_{n} z_{i}-T_{n} z_{j}\right\| .
$$


Since $\left\{T_{n}\right\} \rightarrow T$, we can find $n_{0}, i_{0} \in \mathbf{N}_{0}$ such that for $n(\geq$ $\left.n_{0}\right) \in \mathbf{N}_{0}, \min (i, j)>i_{0}$, we have

$$
\begin{gathered}
\left\|T-T_{n}\right\|<\frac{\varepsilon}{4 c}, \\
\max \left(\left\|z_{i}\right\|,\left\|z_{j}\right\|\right) \leq K_{z} \leq 2 c<\infty, \\
\left\|T_{n} z_{i}-T_{n} z_{j}\right\|<\frac{\varepsilon}{2}
\end{gathered}
$$

for any given $c$ and $\varepsilon=\varepsilon(c) \in \mathbf{R}_{+}$, since $\left\{z_{i}\right\}$ and $\left\{z_{j}\right\}$ are bounded subsequences, and $\left\{T_{n} z_{i}\right\}$ converges, so that it is a Cauchy sequence, since $\left\{T_{n}\right\}$ contains at least one compact operator. As a result, $\left\|T z_{i}-T z_{j}\right\| \leq \varepsilon / 2+\varepsilon / 2=\varepsilon$ is arbitrarily small for $\varepsilon$ being sufficiently small. Thus, $\left\{T z_{i}\right\}$ is convergent. Property (i) has been proven. Property (ii) follows from Property (i) and the fact that any operator composite sequence of bounded operators is a compact operator if there is at least one which is compact.

Now, define the composite operator $\widehat{T}(k+i+1, k): X \rightarrow$ $X$; for all $i, k(\geq i) \in \mathbf{N}_{0}$ by

$$
\begin{array}{r}
\widehat{T}(k+i+1, k)=T_{k+i} \cdots T_{k+1} T_{k} \\
=\left(T_{j_{k+i} k+i} \cdots T_{j_{k+i}-1, k+i} T_{1, k+i}\right) \cdots\left(T_{j_{k} k} \cdots T_{2 k} T_{1 k}\right) ; \\
\forall x \in \operatorname{Dom}\left(T_{10}\right) ; \forall k \in \mathbf{N}_{0} .
\end{array}
$$

Define also the sequence $\left\{\widehat{T}^{0}(k+i+1, k)\right\}$ of composite operators as $\widehat{T}^{0}(k+i+1, k)=T_{k+i}^{0} \cdots T_{k+1}^{0} T_{k}^{0}$; for all $k \in \mathbf{N}_{0}$ where $T_{k+i}^{0}$ replaces each operator in the composite operator $T_{k+i}$ by its limit when such a limit exists. A result is now given based on the existence of the following limit:

$$
\begin{array}{r}
\lim _{k \rightarrow \infty} d\left(\widehat{T}(k+i+1, i) x, \widehat{T}^{0}(k+i+1, i) x\right)=0 ; \\
\forall x \in \operatorname{Dom}\left(T_{10}\right) .
\end{array}
$$

The following result is obtained from Lemmas 4-7.

Theorem 8. Consider the operator composite sequence $\{\widehat{T}(k+$ $i+1, k)\}$; for all $k, i \in \mathbf{N}_{0}$ of composed linear bounded operators in (31) on a Banach space ( $X,\|\|)$, subject to $\operatorname{Im}\left(T_{j k}\right)(\neq \emptyset) \subset \operatorname{Dom}\left(T_{j+1, k}\right)$ for $j \in \overline{j_{k}}, \operatorname{Im} T_{j_{k} k}(\neq \emptyset) \subset$ Dom $T_{1, k+1}$ and $1 \leq j_{k} \leq J\left(\in \mathbf{N}_{0}\right)<\infty$; for all $k \in \mathbf{N}_{0}$, and the sequence of composed linear operators $\left\{\widehat{T}^{0}(k+i+1, k)\right\}$ of defined in the same way as $\{\widehat{T}(k+i+1, k)\}$ as $k \rightarrow \infty$ by replacing each operator possessing a limit by such a limit. The following properties hold.

(i) Either the sequences $\{\widehat{T}(k+i+1, k)\}$ and $\left\{\widehat{T}^{0}(k+i+1, k)\right\}$ have limits and both limits coincide or none of them has a limit and, furthermore, and $\widehat{T}(k+i+1, k) \rightarrow$ $\widehat{T}^{0}(k+i+1, k)$ as $k \rightarrow \infty$.

(ii) If the limits of Property (i) exist and are finite then the limits of the sequences of operators $\{\widehat{T}(k+i+$ $1, k)\}$ and $\left\{\widehat{T}^{0}(k+i+1, k)\right\}$ as $k \rightarrow \infty$; for all $i \in \mathbf{N}_{0}$ have the same set of fixed points. (iii) Assume, in addition, that for some $k \in \mathbf{N}_{0}$, there is at least one compact operator in the composition operator $\widehat{T}(k+i+1, k)$, and that $\operatorname{Im}\left(T_{j k}\right)(\neq \emptyset) \quad \subset$ $\operatorname{Im}\left(\mathrm{T}_{\mathrm{jk}}\right) \subset \operatorname{Dom}\left(\mathrm{T}_{\mathrm{j}+1, \mathrm{k}}\right)$ for $j \in \overline{j_{k}}, \operatorname{Im} T_{j_{k+\ell} k}(\neq \emptyset) \subset$ $\operatorname{Im}_{\mathrm{j}_{\mathrm{k}+\ell} \mathrm{k}}(\neq \emptyset) \subset$ Dom $\mathrm{T}_{1, \mathrm{k}+1}$ for $0 \leq \ell \leq i$ and some $i \in \mathbf{N}_{0}$ and that all the operators are closed. If Property (i) holds with $\widehat{T}(k+i+1, k) \rightarrow \widehat{T}^{0}(k+i+1, k) \rightarrow$ $\widehat{T}^{*}$ as $k \rightarrow \infty$; for some $i \in \mathbf{N}_{0}$ and $\left\|\widehat{T}^{*}\right\| \leq K<1$, then $\widehat{T}^{*}$ is contractive and

$$
\begin{aligned}
& \lim _{k, n \rightarrow \infty}\|\widehat{T}(k+n(i+1), k) x-\widehat{T}((k+n(i+1), k), k) y\| \\
& \quad=\lim _{k \rightarrow \infty}\left\|\widehat{T}^{0}(k+n(i+1), k) x-\widehat{T}^{0}(k+n(i+1), k) y\right\| \\
& \quad=\lim _{k, n \rightarrow \infty}\left\|\widehat{T}^{*^{(i+1) n}} x-\widehat{T}^{*^{(i+1) n}} y\right\|=0 ; \quad \forall x, y \in \operatorname{Dom}\left(T_{10}\right),
\end{aligned}
$$

the sequences of composite operators $\{\widehat{T}(k+j, j)\}$ and $\left\{\widehat{T}^{0}(k+j, j)\right\}$ converge to zero as $k \rightarrow \infty$, and $\widehat{T}^{*}$ : $\operatorname{Dom}\left(\widehat{T}^{*}\right) \subset X \rightarrow \operatorname{Im}\left(\widehat{T}^{*}\right) \subset X$ is bounded, closed and compact and has a unique fixed point in $\operatorname{Dom}\left(\widehat{T}^{*}\right) \cap \operatorname{Im}\left(\mathrm{T}^{*}\right)$ to which all sequences with initial conditions in $\operatorname{Im}\left(\stackrel{\mathrm{T}}{*}^{*}\right)$ converge.

(iv) Assume that there is a (in general, nonunique) strictly increasing sequence of nonnegative integers $\left\{j_{k}\right\}$ with $j_{0}=0$ and $0<j_{k+1}-j_{k} \leq m<\infty$ such that

$$
\begin{aligned}
\left\|\widehat{T}\left(j_{k+2}, j_{k}\right)\right\| & \leq \widehat{K}\left(j_{k+2}, j_{k+1}\right)\left\|\widehat{T}\left(j_{k+1}, j_{k}\right)\right\| \\
& \leq K\left\|\widehat{T}\left(j_{k+1}, j_{k}\right)\right\| ; \quad \forall k \in \mathbf{N}_{0}
\end{aligned}
$$

for some nonnegative real sequence $\left\{K_{k}\left(j_{k+1}, j_{k}\right)\right\} ; k \in$ $\mathbf{N}_{0}$, and some real constant $K \in[0,1)$. Assume, in addition, that for some $k \in \mathbf{N}_{0}$, there is at least one compact operator in any composite operator $\widehat{T}\left(j_{k+1}, j_{k}\right)$ and that all the operators are closed. Then, the sequences of composite operators $\{\widehat{T}(k+j, j)\}$ and $\left\{\widehat{T}^{0}(k+j, j)\right\}$ converge to zero as $k \rightarrow \infty$ for any finite $j \in \mathbf{N}_{0}$. Finally, assume that $\widehat{T}\left(j_{k+1}, j_{k}\right) \rightarrow$ $\widehat{T}_{g}^{*}$ as $k \rightarrow \infty$. Then, $\widehat{T}_{g}^{*}$ is contractive, continuous, bounded, closed, and compact and has a unique fixed point in $\operatorname{Dom}\left(\widehat{T}^{*}\right) \cap \operatorname{Im}\left(\right.$ "“* $\left.^{*}\right)$ to which all sequences with initial conditions in $\operatorname{Im}\left(\right.$ (“) $\left.^{*}\right)$ converge.

Proof. Note from the definition of the sequences $\{\widehat{T}(k+i+$ $1, k)\}$ and $\left\{\widehat{T}^{0}(k+i+1, k)\right\}$ that for any, since

$$
\begin{aligned}
& \left\|\widehat{T}^{0}(k+i+1, k)\right\| \\
& \leq\|\widehat{T}(k+i+1, k)\| \\
& \quad+\left\|\widehat{T}^{0}(k+i+1, k)-T(k+i+1, k)\right\|,
\end{aligned}
$$




$$
\begin{aligned}
\|\widehat{T}(k+i+1, k)\| \\
\leq\left\|\widehat{T}^{0}(k+i+1, k)\right\| \\
\quad+\left\|\widehat{T}^{0}(k+i+1, k)-T(k+i+1, k)\right\|
\end{aligned}
$$

so that $\lim \sup _{k \rightarrow \infty}\left|\|\widehat{T}(k+i+1, k)\|-\left\|\widehat{T}^{0}(k+i+1, k)\right\|\right| \leq 0$. Then, either both sequences of operators $\{\widehat{T}(k+i+1, k)\}$ and $\left\{\widehat{T}^{0}(k+i+1, k)\right\}$ have the same (finite or infinity) limit or none of them has a limit and $\widehat{T}(k+i+1, k) \rightarrow \widehat{T}^{0}(k+i+1, k)$ as $k \rightarrow \infty$. Hence, Property (i). Property (ii) follows trivially from Property (i) for the case $\lim _{k \rightarrow \infty} \widehat{T}^{0}(k+i+1, k)=$ $\lim _{k \rightarrow \infty} \widehat{T}(k+i+1, k)=\widehat{T}^{*}$; for all $i \in \mathbf{N}_{0}$.

To prove Property (iii), note that

$$
\begin{aligned}
& \|\widehat{T}(k+2 i+1, k) x-\widehat{T}(k+2 i+1, k) y\| \\
& \leq K\|x-y\|=K d(x, y), \\
& \| \widehat{T}(k+2 i+1, k+2 i+1) \widehat{T}(k+2 i+1, k) x \\
& -\widehat{T}(k+2 i+1, k+2 i+1) \widehat{T}(k+2 i+1, k) y \| \\
& \leq K^{2}\|x-y\| \\
& \lim _{n \rightarrow \infty} \| \widehat{T}(k+n i+1, k+n i+1) \widehat{T}(k+n i+1, k) x \\
& -\widehat{T}(k+n i+1, k+n i+1) \widehat{T}(k+n i+1, k) y \| \\
& \leq K^{n}\|x-y\|, \\
& d\left(\widehat{T}^{*^{n}} x-\widehat{T}^{*^{n}} y\right) \\
& =d\left(\lim _{k \rightarrow \infty} \widehat{T}(k+n i+1, k) x-\lim _{k \rightarrow \infty} \widehat{T}(k+n i+1, k) y\right) \\
& =\lim _{k \rightarrow \infty} d(\widehat{T}(k+n i+1, k) x-\widehat{T}(k+n i+1, k) y) \\
& =\lim _{k \rightarrow \infty} d(\widehat{T}(k+n i+1, k) x, \widehat{T}(k+n i+1, k) y) \\
& =\lim _{k \rightarrow \infty} d\left(\widehat{T}^{0}(k+n i+1, k) x, \widehat{T}^{0}(k+n i+1, k) y\right) \\
& =\lim _{k \rightarrow \infty} d\left(\widehat{T}(k+n i+1, k) x, \widehat{T}^{0}(k+n i+1, k) y\right) \\
& =\lim _{k \rightarrow \infty}\|\widehat{T}(k+n i+1, k) x-\widehat{T}(k+n i+1, k) y\| \\
& \leq K^{n} d(x, y)
\end{aligned}
$$

so that, since $K \in[0,1)$ then the limit operator $\widehat{T}^{*}$ on $X$ is continuous, then bounded with

$$
\lim _{n \rightarrow \infty} d\left(\widehat{T}^{*^{n}} x-\widehat{T}^{*^{n}} y\right)=d\left(\lim _{n \rightarrow \infty} \widehat{T}^{*^{n}} x-\lim _{n \rightarrow \infty} \widehat{T}^{*^{n}} y\right)=0
$$

for any $x, y \in \operatorname{Dom}\left(T_{10}\right)$. Furthermore, for any $k \in \mathbf{N}_{0}$ and the associative property of composition of operators, $\exists n=n(j, k)=\max \left(i \in \mathbf{Z}_{0+}: \widehat{T}(k+j, j)=\widehat{T}\left(k+j, k_{1}\right)\right.$ $\widehat{T}^{*^{n}}\left(k_{2}, j\right)$; for all $j \in \mathbf{N}_{0}$, for all $\left.k(>j) \in \mathbf{N}\right)$ with $n=n(j, k)$ being unique for each given $j \in \mathbf{N}_{0}, k(>j) \in \mathbf{N}$ and the given operator decomposition being also trivially unique. Note that $\|\widehat{T}(k+j, j)\| \rightarrow 0$ as $k \rightarrow \infty$ for any $j \in \mathbf{N}_{0}$ since $n=$ $n(j, k) \rightarrow \infty$ if $(k-j) \rightarrow \infty$ since $\left\|\widehat{T}^{*^{n}}\right\| \leq K^{n} \rightarrow$ 0 as $n \rightarrow \infty$ since $K \in[0,1)$. Similarly, it is proven that $\left\|\widehat{T}^{0}(k+j, j)\right\| \rightarrow 0$ as $k \rightarrow \infty$.

On the other hand, note the following.

(1) Any convergent sequence $\left\{x_{k}\right\}$ for $k \in \mathbf{N}_{0}$ constructed from the composed operators

$$
\begin{aligned}
& \widehat{T}(k+i+1, k)=T_{k+i} \cdots T_{k+1} T_{k} \\
& \quad=\left(T_{j_{k+i} k+i} \cdots T_{j_{k+i}-1, k+i} T_{1, k+i}\right) \cdots\left(T_{j_{k} k} \cdots T_{2 k} T_{1 k}\right)
\end{aligned}
$$

for any $k \in \mathbf{N}_{0}$ as follows $x_{1 k} \in \operatorname{Dom}\left(T_{1 k}\right), x_{2 k}=$ $T_{2 k} x_{1 k}, \ldots, x_{j_{k} k}=T_{j_{k} k} x_{j_{k}-1, k}, x_{1, k+1}=T_{1, k+1}$ $x_{j_{k} k}, \ldots$ converges to a point $\bar{x}$ in $\operatorname{Dom}\left(\widehat{T}^{*}\right)$, since all the operators in the above composite sequence of operators are closed and then the limit operator $\widehat{T}^{*}$ : $\operatorname{Dom}\left(\widehat{T}^{*}\right) \subset X \rightarrow \operatorname{Im}\left(\widehat{\mathrm{T}}^{*}\right) \subset \operatorname{Im}\left(\widehat{T}^{*}\right) \subset \operatorname{Dom}\left(\widehat{T}^{*}\right) \subset$ $X$ is also bounded and closed (from Lemma 6 and the associative property of operator compositions), and $\widehat{T}^{*} \bar{x}$ in $\operatorname{Im}\left(\widehat{T}^{*}\right) \subset \operatorname{Im}\left(\widehat{T}^{*}\right)$ with $\operatorname{Im}\left(\widehat{T}^{*}\right)$ being closed (i.e., $\operatorname{Im}\left(\widehat{T}^{*}\right)$ is relatively compact) since all composite sequences of operators $\widehat{T}(k+j, j)$ are compact for any given $j \in \mathbf{N}_{0}, k(>j) \in \mathbf{N}$ since at least one of the operators within any of such sequences is compact and all of them are bounded, $[1,3,4]$.

(2) Any convergent sequence $\left\{\widehat{T}^{* n} x\right\}$ of elements in $\operatorname{Dom}\left(\widehat{T}^{*}\right)$ with $x \in \operatorname{Dom}\left(T_{10}\right)$ converges to some point $x^{*}$ in $\operatorname{Dom}\left(\widehat{T}^{*}\right)$, which maps to $\widehat{T}^{*} x^{*}$ in $\operatorname{Im}\left(\widehat{T}^{*}\right) \subset \operatorname{Im}\left(\widehat{T}^{*}\right) \subset \operatorname{Dom}\left(\widehat{T}^{*}\right)$ which is also the limit of the same convergent sequence. Such a limit $\left\{\widehat{T}^{*^{n}} x\right\}$ has a limit in $\operatorname{Dom}\left(\widehat{T}^{*}\right) \cap \operatorname{Im}\left(\widehat{T}^{*}\right)$ which is also the unique fixed point of $\widehat{T}^{*}$. Otherwise, if there were two distinct fixed points $x^{*}$ and $y^{*}$ then it would are $x, y \in \operatorname{Dom}\left(T_{10}\right)$ such that $\lim _{n \rightarrow \infty} d\left(\widehat{T}^{*^{n}} x-\right.$ $\left.\widehat{T}^{*^{n}} y\right)=d\left(x^{*}, y^{*}\right)>0$, then a contradiction and hence Property (iii).

To prove Property (iv), note that strictly increasing sequence of nonnegative integers $\left\{j_{k}\right\}$ with $j_{0}=0$ and $0<$ $j_{k+1}-j_{k} \leq m<\infty$ such that

$$
\begin{aligned}
& \left\|\widehat{T}\left(j_{k+1}, 0\right)\right\| \leq K^{j_{k}}\left\|\widehat{T}\left(j_{1}, 0\right)\right\| \longrightarrow 0 \quad \text { as } k \longrightarrow \infty ; \\
& \left\|\widehat{T}\left(j_{k+1}+m_{k}, 0\right)\right\| \leq M K^{j_{k}}\left\|\widehat{T}\left(j_{1}, 0\right)\right\| \longrightarrow 0
\end{aligned}
$$

for any sequence of nonnegative integers $\left\{m_{k}\right\}$ subject to $0 \leq m_{k}<j_{k+2}-j_{k+1} \leq m<\infty$; for all $k \in \mathbf{N}_{0}$ for some nonnegative real sequence $\left\{K_{k}\left(j_{k+1}, j_{k}\right)\right\} ; k \in \mathbf{N}_{0}$ and some real constant $K \in[0,1)$. As a result the sequences of 
composite operators $\{\widehat{T}(k, 0)\},\left\{\widehat{T}^{0}(k, 0)\right\},\{\widehat{T}(k+j, j)\}$, and $\left\{\widehat{T}^{0}(k+j, j)\right\}$ converge to zero as $k \rightarrow \infty$ for any finite $j \in \mathbf{N}_{0}$. On the other hand, if $\widehat{T}\left(j_{k+1}, j_{k}\right) \rightarrow \widehat{T}_{g}^{*}$ as, $k \rightarrow$ $\infty$ then $\widehat{T}_{g}^{*}$ is contractive. Otherwise, it would hold trivially that $\lim \inf _{k \rightarrow \infty}\|\widehat{T}(k, 0)\|>0$, a contradiction. Thus, the limit operator $\widehat{T}_{g}^{*}$ is contractive and bounded and then it is also continuous as a result. $\widehat{T}_{g}^{*}: \operatorname{Dom}\left(\widehat{T}_{g}^{*}\right) \subset X \rightarrow \operatorname{Im}\left(\widehat{T}_{g}^{*}\right) \subset$ $\operatorname{Im}\left(T_{g}^{*}\right) \subset \operatorname{Dom}\left(\widehat{T}_{g}^{*}\right) \subset X$ is closed (from Lemma 6) and compact, since all the operators in the composite sequence of operators $T\left(j_{k+1}, j_{j}\right)$ are bounded and at least one of them is compact. Thus, $\widehat{T}_{g}^{*}$ has a unique fixed point in $\operatorname{Dom}\left(\widehat{T}^{*}\right) \cap \operatorname{Im}\left(\widehat{T}^{*}\right)$ to which all sequences to which all the sequences $\left\{x_{k}\right\} ; k \in \mathbf{N}_{0}$ of the form $x_{1 k} \in \operatorname{Dom}\left(T_{1 k}\right), x_{2 k}=$ $T_{2 k} x_{1 k}, \ldots, x_{j_{k} k}=T_{j_{k} k} x_{j_{k}-1, k}, x_{1, k+1}=T_{1, k+1} x_{j_{k} k}, \ldots$ with initial point in Dom $T_{10}$ converge. Hence, Theorem 8 is fully proven.

Remark 9. Note that the existence of the operator limits in Theorem 8 [(iii)-(iv)] is not required for each operator within the composite sequence of operators but only for certain composite strips of such operators.

The subsequent result, whose proof is omitted, extends in a natural way Theorem 8 through the associative property of composite operators to the case that there are subsets of composite operators having limits although each individual operator is not requested to have a limit.

Theorem 10. Consider the composite operator below:

$$
\begin{aligned}
& \widehat{T}\left(k+i_{k}+1, k\right)=T_{k+i_{k}} \cdots T_{k+1} T_{k} \\
& \quad=\left(T_{j_{k+i_{k}} k+i} \cdots T_{j_{k+i_{k}}-1, k+i} T_{1, k+i_{k}}\right) \cdots\left(T_{j_{k} k} \cdots T_{2 k} T_{1 k}\right),
\end{aligned}
$$

on a Banach space $(X,\|\|)$, subject to the following conditions.

(1) The elements of the sequences of sets $\left\{i_{k}\right\}$ are finite and each of those sets has a finite cardinal for all $k \in \mathbf{N}_{0}$, and $i_{k} \rightarrow i^{*}(<\infty)$ as $k \rightarrow \infty$.

(2) $\operatorname{Im}\left(T_{j k}\right)(\neq \emptyset) \subset \operatorname{Im}\left(T_{j k}\right) \subset \operatorname{Dom}\left(T_{j+1, k}\right)$ for $j \in$ $\overline{j_{k}}, \operatorname{Im} T_{j_{k+e}}(\neq \emptyset) \subset \operatorname{ImT}_{j_{\mathrm{k}+\ell} \mathrm{k}}(\neq \emptyset) \subset \operatorname{Dom~T}_{1, \mathrm{k}+1}$ for $0 \leq \ell \leq i_{k}$.

(3) The elements of the sequences of nonnegative integers $\left\{j_{k+i_{k}}\right\}$ are finite for all $k \in \mathbf{N}_{0}$, and $j_{k+\ell_{k}} \rightarrow$ $j_{k+\ell}$ for $0 \leq \ell_{k} \leq i_{k}, 0 \leq \ell \leq i^{*}$ as $k \rightarrow \infty$.

(4) All the operators in each of the sets $\left\{T_{i_{k} k}: 1 \leq i_{k} \leq\right.$ $\left.j_{k}\right\}$; for all $k \in \mathbf{N}_{0}$ are linear, bounded, and closed (so that all the operators are linear, bounded, and closed) and at least one of them in each set is compact.

(5) The sequences of composite operators $\left\{T_{k+\ell_{k}}\right\}$ for $0 \leq$ $\ell_{k} \leq i_{k}$; for all $k \in \mathbf{N}_{0}$ tend to respective limit operators $T_{j}^{*}$ for $0 \leq j \leq i^{*}$ as $k \rightarrow \infty$.

Then, $\widehat{T}\left(k+i_{k}+1, k\right) \rightarrow \widehat{T}\left(k+i^{*}+1, k\right) \rightarrow T^{*}=$ $T_{i}^{*} \cdots T_{2}^{*} T_{1}^{*}$ which is linear, continuous, bounded, closed, and compact. Furthermore, if $\left\|T_{j}^{*}\right\| \leq K_{j}$ and $K=\prod_{j=0}^{i^{*}} K_{j}<1$, then $T^{*}$ has a unique fixed point in Dom $T^{*} \cap \mathrm{Im}^{*}$ to which all sequences $\left\{x_{k}\right\} ; k \in \mathbf{N}_{0}$ of the form $x_{1 k} \in \operatorname{Dom}\left(T_{1 k}\right), x_{2 k}=$ $T_{2 k} x_{1 k}, \ldots, x_{j_{k} k}=T_{j_{k} k} x_{j_{k}-1, k}, x_{1, k+1}=T_{1, k+1} x_{j_{k} k}, \ldots$ with initial point in Dom $T_{10}$ converge.

Example 11. This example discusses a way to use oblique projections to build composite operators with sequences of operators to take into account the approximation of the images in finite-dimensional spaces and also to take account of computing or measurement errors as well as connections with fixed point issues. Consider the complex pre-Hilbert space $L_{p}^{2}(a)$ of square-integrable $p$-vector functions on $[0, a]$ endowed with an inner product defined by the complex number $\langle x, y\rangle$; for all $x, y \in L_{p}^{2}(a)$ with associate inner product induced norm $\|x\|=\langle x, x\rangle^{1 / 2}$; for all $x \in L_{p}^{2}(a)$. Consider a bounded linear operator $T: L_{p}^{2}(a) \rightarrow L_{p}^{2}(a)$, of norm $\|T\|=\sup _{\|x\|=1}\|T x\|$, represented by $y(t)=(T x)(t)=$ $\sum_{i=1}^{\infty}\left\langle y, \theta_{i}\right\rangle \varphi_{i}(t)$; for all $t \in[0, a]$, where $\varphi_{i}, \theta_{i}:[0, a] \rightarrow$ $L_{p}^{2}(a) ; i \in \mathbf{N}$ are sets of linearly independent functions which define mutually reciprocal basis $\left\{\varphi_{i}: i \in \bar{n}\right\}$ and $\left\{\theta_{i}: i \in \bar{n}\right\}$, that is, $\left\langle\theta_{i}, \varphi_{i}\right\rangle=\delta_{i j}$. If such basis are orthogonal then they are identical leading to $y(t)=(T x)(t)=$ $\sum_{i=1}^{\infty}\left\langle y, \varphi_{i}\right\rangle \varphi_{i}(t)$; for all $t \in[0, a]$. We can decompose $L_{p}^{2}(a)$ uniquely as a direct sum of orthogonal subspaces as follows as $L_{p}^{2}(a)=M_{n} \oplus\left(L_{p}^{2}(a) \cap M_{n}\right)$ for each $n \in \mathbf{N}$ where the orthogonal projection of $T: L_{p}^{2}(a) \rightarrow L_{p}^{2}(a)$ on $M_{n} \subset L_{p}^{2}(a)$ is given by the composite operator $P_{n} T_{n}$ : $L^{2}(a) \rightarrow M_{n}$ of the orthogonal projection $P_{n}: L^{2}(a) \rightarrow M_{n}$ represented by $\hat{y}_{n}(t)=\left(P_{n} \bar{y}_{n}\right)(t)$, where $\bar{y}_{n}(t)=\left(T_{n} x\right)(t)=$ $\sum_{i=1}^{n}\left\langle y, \theta_{i}\right\rangle \varphi_{i}(t)$, for all $t \in[0, a]$ is defined through the truncated operator $T_{n}: L_{p}^{2}(a) \rightarrow L_{p}^{2}(a)$ so that

$$
\begin{aligned}
\widehat{y}_{n}(t)=\left(P_{n} T_{n} x\right)(t) & =\left(\sum_{i=1}^{n}\left\langle P_{n} T x, \theta_{i}\right\rangle \varphi_{i}\right)(t) \\
& =\left(\sum_{i=1}^{n} \sum_{j=1}^{n}\left\langle P_{n} T \varphi_{j}, \theta_{i}\right\rangle \alpha_{j} \varphi_{i}\right)(t) \\
& =\sum_{i=1}^{n} \beta_{i} \varphi_{i}(t),
\end{aligned}
$$

where

$$
\begin{aligned}
\alpha_{i} & =\left\langle x, \theta_{j}\right\rangle \\
\beta_{i} & =\sum_{j=1}^{n}\left\langle P_{n} T \varphi_{j}, \theta_{i}\right\rangle \alpha_{j} \\
& =\sum_{j=1}^{n}\left\langle P_{n} T \varphi_{j}, \theta_{i}\right\rangle\left\langle x, \theta_{j}\right\rangle ; \quad i \in \bar{n}=\{1,2, \ldots, n\} .
\end{aligned}
$$

Note that $\left\{T_{n}\right\} \rightarrow T$ and $d\left(y, \hat{y}_{n}\right)(t) \rightarrow 0$ as $n \rightarrow$ $\infty$; for all $t \in[0, a]$. Now assume that $y(t)$ is subject to some structured uncertainty $\tilde{y}(t)=(\widetilde{T} T x)(t)=\sum_{i=1}^{\infty}\left\langle\widetilde{y}, \varphi_{i}\right\rangle \varphi_{i}(t)=$ 
$\left(\sum_{i=1}^{\infty}\left\langle T \widetilde{T} x, \varphi_{i}\right\rangle\right) \varphi_{i}(t)$; for all $t \in[0, a]$ (due, for instance, to computational or measurement errors) and defined by some relative uncertainty operator $\widetilde{T}$ in $\widetilde{\mathbf{T}}$ on $L_{p}^{2}(a)$ belonging to a family $\widetilde{\mathbf{T}}=\left\{\widetilde{T} \in L_{p}^{2}(a):\|\widetilde{T}\| \leq \widetilde{t}\right.$, some $\left.\widetilde{t} \in \mathbf{R}_{0+}\right\}$ so that $y_{\text {mes }}(t)=y(t)+\tilde{y}(t)$ and its projected value on $M_{n}$, through the orthogonal projection $M_{n}$, is

$$
\begin{aligned}
\widehat{y}_{\text {mes }_{n}} & (t) \\
= & \left(P_{n}\left(T_{n}+\widetilde{T}_{n} T_{n}\right) x\right)(t) \\
= & \left(P_{n} T_{n} x\right)(t)+\left(P_{n} \widetilde{T}_{n} T_{n}\right) x(t) \\
= & \widehat{y}_{n}(t)+\widetilde{y}_{n}(t) \\
= & \left(\sum_{i=1}^{n}\left\langle P_{n}(T+\widetilde{T} T) x, \theta_{i}\right\rangle \varphi_{i}\right)(t) \\
= & \left(\sum_{i=1}^{n} \sum_{i=1}^{n}\left\langle P_{n} T \varphi_{j}+P_{n} \widetilde{T}_{T} \varphi_{j}, \theta_{i}\right\rangle \alpha_{j} \varphi_{i}\right)(t) \\
= & \left(\sum_{i=1}^{n} \sum_{i=1}^{n}\left\langle P_{n}(I+\widetilde{T}) T \varphi_{j}, \theta_{i}\right\rangle \alpha_{j} \varphi_{i}\right)(t) \\
= & \sum_{i=1}^{n}\left(\beta_{i}+\widetilde{\beta}_{i}\right) \varphi_{i}(t) ; \quad \forall t \in[0, a], \\
\widehat{y}_{\text {mes }_{n}} & (t)-\widehat{y}_{n}(t) \\
= & \left(\sum_{i=1}^{n} \sum_{j=1}^{n}\left\langle P_{\text {on }_{i}}(\widetilde{T}) T \varphi_{j}, \theta_{i}\right\rangle \alpha_{j} \varphi_{i}\right)(t) \\
& \\
&
\end{aligned}
$$

where $\left\{\widetilde{T}_{n}\right\} \rightarrow \widetilde{T}$,

$$
\begin{array}{r}
\widetilde{\beta}_{i}(t)=\sum_{j=1}^{n}\left\langle P_{n} \widetilde{T} T \varphi_{j}, \theta_{i}\right\rangle \alpha_{j}(t) \\
=\sum_{j=1}^{n}\left\langle P_{n} \widetilde{T} T \varphi_{j}, \theta_{i}\right\rangle\left\langle x, \theta_{j}\right\rangle(t) ; \\
i \in \bar{n}=\{1,2, \ldots, n\}
\end{array}
$$

with $P_{\text {on }}\left(\widetilde{T}_{n}\right)=P_{n}\left(I+\widetilde{T}_{n}\right)$ is an oblique operator which depends on the particular uncertainty operator $\widetilde{T}_{n}$ in the class $\widetilde{\mathbf{T}}$ which has necessarily a norm exceeding unity while the orthogonal operator $P_{n}$ has unit norm. The (non-necessarily unique) worst case in a norm deviation sense of the measured projection of $y$ on the subspace $M_{n}$ is given by

$$
\widehat{y}_{\text {mes }_{n}}^{w}(t)=\sup _{\widetilde{T} \in \widetilde{T}} \sum_{i=1}^{n} \sum_{j=1}^{n}\left\langle P_{\text {on }}^{w}(\widetilde{T}) T \varphi_{j}, \theta_{i}\right\rangle \alpha_{j} \varphi_{i}(t)
$$

so that the maximum deviation amount of the projected vector is

$$
\begin{aligned}
\left\|\widehat{y}_{\text {mes }_{n}}^{w}-\widehat{y}_{n}\right\| & =\left\|\sum_{i=1}^{n} \sum_{j=1}^{n}\left\langle P_{\text {on }}^{w}(\widetilde{T}) T \varphi_{j}, \theta_{i}\right\rangle \alpha_{j} \varphi_{i}\right\| \\
& =\sup _{\widetilde{T} \in \widetilde{T}}\left\|\sum_{i=1}^{n} \sum_{j=1}^{n}\left\langle P_{\text {on }}(\widetilde{T}) T \varphi_{j}, \theta_{i}\right\rangle \alpha_{j} \varphi_{i}\right\| .
\end{aligned}
$$

If the basis $\left\{\varphi_{i}: i \in \bar{n}\right\}$ is orthonormal then it is autoreciprocal, then all its vector functions have unit norm and

$$
\begin{aligned}
\widehat{y}_{\text {mes }_{n}}^{w}(t) & =\sup _{\widetilde{T} \in \widetilde{\mathrm{T}}} \sum_{i=1}^{n} \sum_{j=1}^{n}\left\langle P_{\text {on }}^{w}(\widetilde{T}) T \varphi_{j}, \varphi_{i}\right\rangle \alpha_{j} \varphi_{i}(t), \\
\left\|\widehat{y}_{\text {mes }_{n}}^{w}-\widehat{y}_{n}\right\| & =\left\|\sum_{i=1}^{n} \sum_{j=1}^{n}\left\langle P_{\text {on }}^{w}(\widetilde{T}) T \varphi_{j}, \varphi_{i}\right\rangle \alpha_{j} \varphi_{i}\right\| \\
& =\sup _{\widetilde{T} \in \widetilde{T}}\left\|\sum_{i=1}^{n} \sum_{j=1}^{n}\left\langle P_{\text {on }}(\widetilde{T}) T \varphi_{j}, \varphi_{i}\right\rangle \alpha_{j} \varphi_{i}\right\| .
\end{aligned}
$$

The problem can be reformulated for the case $a=$ $\infty$ for $T: L_{p}^{2} \rightarrow L_{p}^{2}$ being a bounded linear operator on the Hilbert (then complete) space $L_{p}^{2}$. Thus, $T: L_{p}^{2} \rightarrow L_{p}^{2}$ is closed, since bounded, and its domain is $L_{p}^{2}$ and it is also guaranteed to be compact from of its representation. It is clear that the operators in the sequence $\left\{T_{n}\right\}$ are bounded, closed, compact, of closed range so that their ranges have $n$-finite dimension and their domain is $L_{p}^{2}$. The orthogonal and oblique operators involved in the above discussion are all bounded and of closed ranges. Then, all the composite operators of the forms $\left\{P_{n} T\right\},\left\{P_{\text {on }} T\right\},\left\{P_{\text {on }} \widetilde{T} T\right\}$ and the operators in the converging sequences $\left\{P_{n} T_{n}\right\},\left\{P_{\text {on }} T_{n}\right\},\left\{P_{\text {on }} \widetilde{T}_{n} T_{n}\right\}$ are all bounded, closed, and compact of domain $L_{p}^{2}$. If $\|T\| \leq K<1$ then for any given real $\varepsilon \in(0,1-K)$ there is $n_{0} \in \mathbf{N}_{0}$ such that $\left\|T_{n}\right\| \leq K+\varepsilon<1$ since $\left\{T_{n}\right\} \rightarrow T$. Assume that the class of uncertainty operators $\widetilde{T}_{n}$ in the class $\widetilde{\mathbf{T}}$ on $L_{p}^{2}$ has the property $\left\|P_{\text {on }}\left(\widetilde{T}_{n}\right)\right\|=\left\|I+\widetilde{T}_{n}\right\| \leq\left\|P_{\text {on }}^{w}\right\| \leq 1 /(K+\varepsilon)<$ 1 ; for all $n>n_{0}$. Thus, the composite operators $P_{\text {on }}\left(\widetilde{T}_{n}\right) T_{n}$ are contractive if $\left\|I+\widetilde{T}_{n}\right\| \leq 1 / K+\varepsilon<1$; for all $n>n_{0}$ and each of such composite operators has a unique fixed point, which depends on $n$; for all $n>n_{0}$ and which converges to the unique fixed point of the contractive operator $(I+$ $\widetilde{T}) T$ as $n \rightarrow \infty$ from Theorem 8 since $\left(I+\widetilde{T}_{n}\right) T_{n} \rightarrow(I+$ $\widetilde{T}) T$ as $n \rightarrow \infty$ so that $d\left(\left(I+\widetilde{T}_{n}\right)^{n} T_{n}^{n} z,(I+\widetilde{T})^{n} T^{n} z\right) \rightarrow$ 0 and $d\left((I+\widetilde{T})^{n} T^{n} y,(I+\widetilde{T})^{n} T^{n} z\right) \rightarrow 0$ as $n \rightarrow \infty$ for any $y, z \in L_{p}^{2}$.

Remark 12. Some ideas in Example 11 combining uncertainties with projections both being described through "ad hoc" operators are useful in problems of Signal Theory and Control Systems Theory, [4]. Some related problems can be combined with stability and stabilization issues of dynamic systems subject to unmodeled dynamics and/or parametrical-type uncertainties by using Lyapunov stability theory and fixed 
point analysis. See, for instance, [7-10]. Fixed point analysis can also be a useful technical tool when using iterative methods in numerical approaches. See, for instance, [11, 12] and references therein. It can be direct the extension of the results to a formalism concerning the replacement of fixed points by best proximity points of cyclic $p$-self-mappings [13-17] on unions of sets which do not intersect since best proximity points are also fixed points of certain strips of fixed length $p$ of companion composite self-mappings $T^{p}$ : $\bigcup_{i \in \bar{p}} A_{i} \rightarrow \bigcup_{i \in \bar{p}} A_{i}$ with themselves, the sizes $p$ of such composite self-mappings being the number of disjoint sets $A_{\mathrm{i}} \subset X, i \in \bar{p}:=\{1,2, \ldots, p\}$ in the cyclic disposal. The location of fixed points has also been approximated in some background bibliography on the field. See $[18,19]$ and references there in. In particular, approximated fixed points have been characterized for nonself mappings which do not possess fixed points. See, for instance, [19] and references therein.

\section{Acknowledgment}

The author thanks the Spanish Ministry of Education for its support of this work through Grant DPI2012-30651. He is also grateful to the Basque Government for its support through Grants GIC 07143-IT-269-07 and SAIOTEK SPE12UN015 and to UPV/EHU for its support through UFI 11/07.

\section{References}

[1] A. Granas and J. Dugundji, Fixed Point Theory, Springer Monographs in Mathematics, Springer, New York, NY, USA, 2003.

[2] T. A. Burton, Stability by Fixed Point Theory for Functional Differential Equations, Dover Publications, New York, NY, USA, 2006.

[3] R. E. Edwards, Functional Analysis. Theory and Applications, Dover Publications, Toronto, Canada, 1995.

[4] A. Feintuch, Robust Control Theory in Hilbert Space, Springer, New York, NY, USA, 1998.

[5] S. Plubtieng and R. Punpaeng, "A general iterative method for equilibrium problems and fixed point problems in Hilbert spaces," Journal of Mathematical Analysis and Applications, vol. 336, no. 1, pp. 455-469, 2007.

[6] S. Plubtieng and R. Punpaeng, "A new iterative method for equilibrium problems and fixed point problems of nonexpansive mappings and monotone mappings," Applied Mathematics and Computation, vol. 197, no. 2, pp. 548-558, 2008.

[7] M. Ratchagit and K. Ratchagit, "Asymptotic stability and stabilization of fixed points for iterative sequence," International Journal of Research and Reviews in Computer Science, vol. 2, no. 4, pp. 987-989, 2011.

[8] M. De la Sen, "Total stability properties based on fixed point theory for a class of hybrid dynamic systems," Fixed Point Theory and Applications, vol. 2009, Article ID 826438, 19 pages, 2009.

[9] V. N. Phat, Y. Khongtham, and K. Ratchagit, "LMI approach to exponential stability of linear systems with interval timevarying delays," Linear Algebra and its Applications, vol. 436, no. 1, pp. 243-251, 2012.
[10] V. N. Phat and K. Ratchagit, "Stability and stabilization of switched linear discrete-time systems with interval timevarying delay," Nonlinear Analysis. Hybrid Systems, vol. 5, no. 4, pp. 605-612, 2011.

[11] A. Cordero and J. R. Torregrosa, "Variants of Newton's method using fifth-order quadrature formulas," Applied Mathematics and Computation, vol. 190, no. 1, pp. 686-698, 2007.

[12] A. Cordero and J. R. Torregrosa, "Variants of Newton's method for functions of several variables," Applied Mathematics and Computation, vol. 183, no. 1, pp. 199-208, 2006.

[13] C.-M. Chen and W. Y. Sun, "Periodic points and fixed points for the weaker $(\phi, \phi)$-contractive mappings in complete generalized metric spaces," Journal of Applied Mathematics, vol. 2012, Article ID 856974, 7 pages, 2012.

[14] E. Karapinar and K. Saradangani, "Fixed point theory for cyclic $(\phi, \psi)$-contractions," Fixed Point Theory and Applications, vol. 2011, article 69, 2011.

[15] M. De la Sen, "Linking contractive self-mappings and cyclic Meir-Keeler contractions with Kannan self-mappings," Fixed Point Theory and Applications, vol. 2010, Article ID 572057, 23 pages, 2010.

[16] A. Abkar and M. Gabeleh, "Results on the existence and convergence of best proximity points," Fixed Point Theory and Applications, vol. 2010, Article ID 386037, 10 pages, 2010.

[17] E. Karapınar, İ. M. Erhan, and A. Y. Ulus, "Fixed point theorem for cyclic maps on partial metric spaces," Applied Mathematics \& Information Sciences, vol. 6, no. 2, pp. 239-244, 2012.

[18] H. H. Bauschke, "The approximation of fixed points of compositions of nonexpansive mappings in Hilbert space," Journal of Mathematical Analysis and Applications, vol. 202, no. 1, pp. 150159, 1996.

[19] S. Sadiq Basha, N. Shahzad, and R. Jeyaraj, "Optimal approximate solutions of fixed point equations," Abstract and Applied Analysis, vol. 2011, Article ID 174560, 9 pages, 2011. 


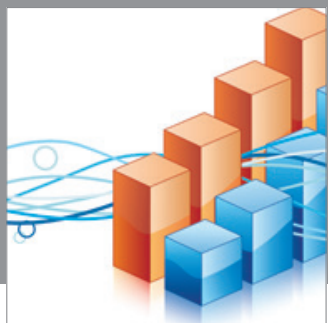

Advances in

Operations Research

mansans

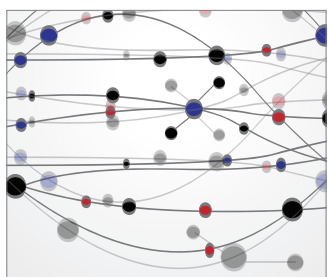

The Scientific World Journal
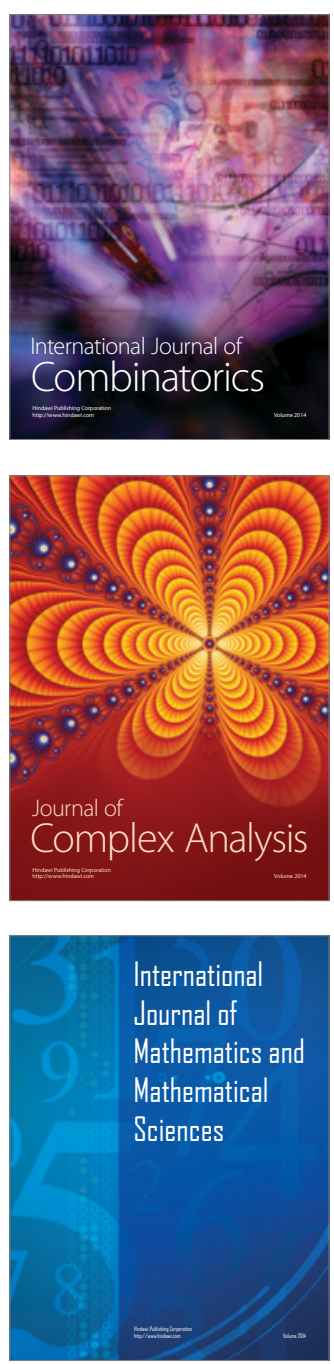
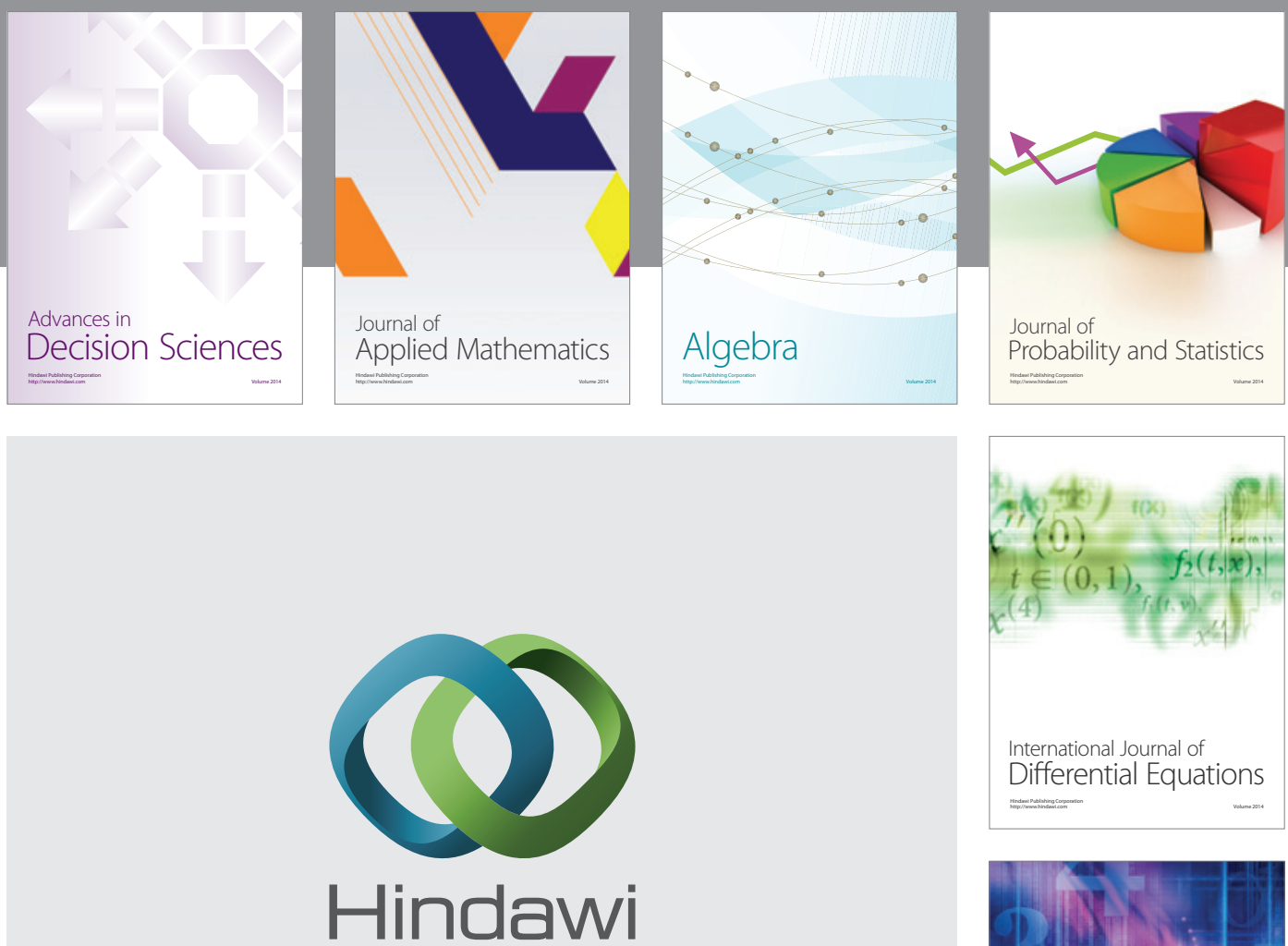

Submit your manuscripts at http://www.hindawi.com
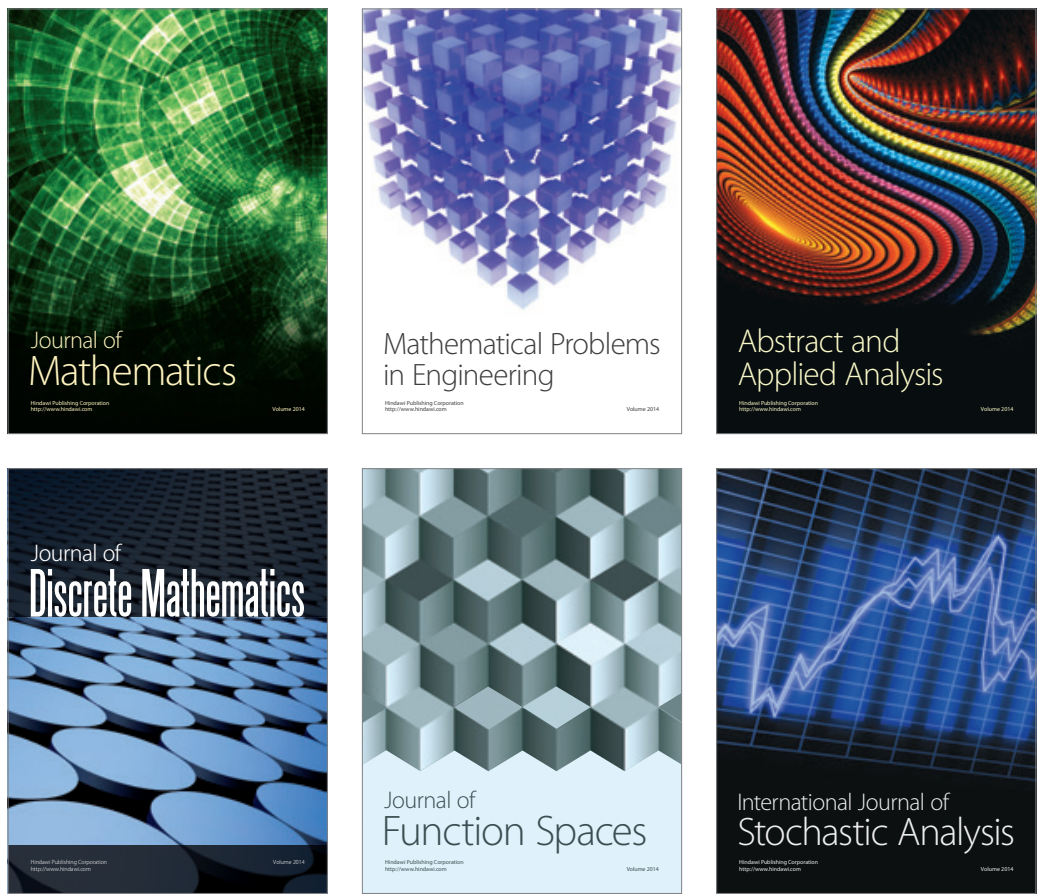

Journal of

Function Spaces

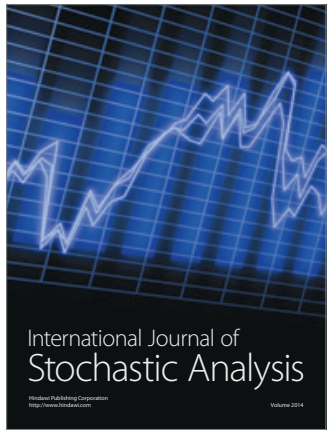

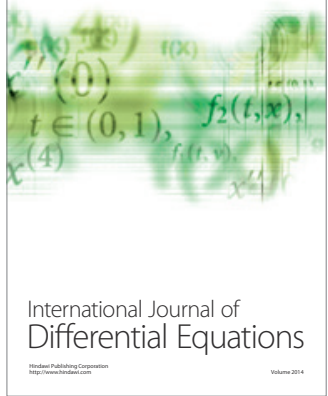
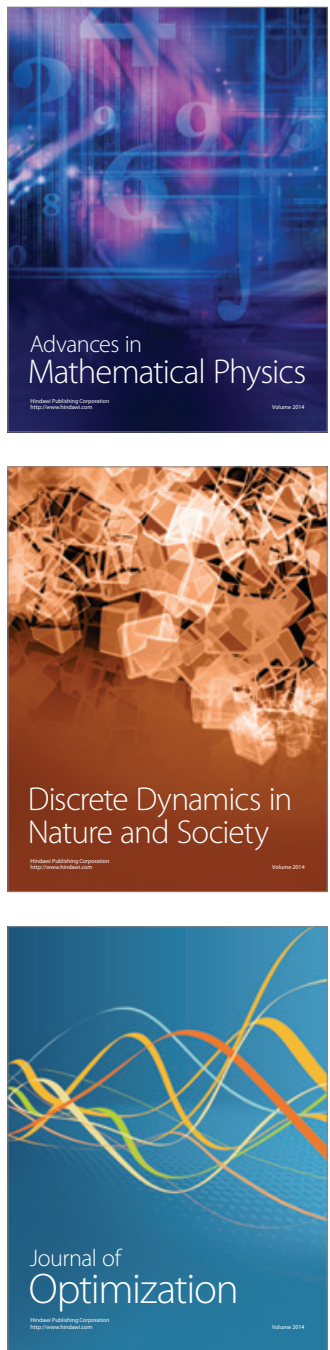